\title{
PALEOAMBIENTES E ICNOFÁCIES DA SEQÜÊNCIA CARBONÁTICA DA BACIA DA PARAÍBA (CRETÁCEO-PALEOGENO), NORDESTE DO BRASIL
}

\author{
JOSÉ ANTONIO BARBOSA', MARIA SOMÁLIA SALES VIANA ${ }^{2}$ \& \\ VIRGÍNIO HENRIQUE NEUMANN ${ }^{3}$
}

\begin{abstract}
Resumo Este trabalho apresenta uma investigação detalhada dos aspectos estratigráficos, sedimentológicos e paleontológicos. principalmente icnofaciológicos, em afloramentos de rochas carbonáticas das formações Gramame e Maria Farinha, na Bacia da Paraíba, nordeste do Brasil. A Formação Gramame foi depositada em um regime de mar alto, abaixo do nível de base de ondas de bom tempo, em ambiente de baixa energia sujeito a eventos de tempestade com predomínio de substrato macio e, icnofácies Cruziana. A Formação Maria Farinha, por sua vez, foi depositada durante um evento de regressão, com aumento de energia e redução da lâmina d’água, que provocou variações laterais de sua faciologia e, icnofácies correspondente a Cruziana-Skolithos. Os calcários recifais, de provável idade eocênica, encontrados na Paraíba apresentam expressiva diferença dos calcários da Formação Maria Farinha típica, podendo representar uma outra unidade. Estes calcários estão separados da Formação Maria Farinha por discordância e indicam o estabelecimento de um trato de mar baixo, e icnofácies interpretada como Trypanites?. A integração dos dados sugere uma paleobatimetria de plataforma intermediária a interna $(150-80 \mathrm{~m})$, para a Formação Gramame, e de plataforma interna a infralitoral (60-20m), incluindo proximidade de estuários, para a Formação Maria Farinha.
\end{abstract}

Palavras-Chave: Bacia da Paraíba, icnofácies, Formação Gramame, Formação Maria Farinha

\begin{abstract}
PALAEOENVIRONMENTS AND ICHNOFACIES OF THE CARBONATE SEQUENCE OF PARAÍBA BASIN (CRETACEOUS-PALEOGENE), NE BRASIL - This work deals an investigation of the stratigraphic, sedimentological and paleontological aspects, mainly ichnologic, in outcrops of carbonate deposits of the Gramame and Maria Farinha formations in the Paraíba Basin, northeast Brazil. The objective of the investigation was to obtain detailed information on the depositional environments of these units. The Gramame Formation was deposited in a regime of highstandstand system tract, belowstand the base level of fair weather waves where prevailed conditions of soft bottom and lowstand energy, but often reached by storm events, correlated to the Cruziana ichnofacies. The Maria Farinha Formation was deposited during a regressive event, with the increase of energy and siliciclastic input, important lateral facies variation and Cruziana-Skolithos ichnofacies. The eocenic carbonate rocks, that occur in the south coast of Paraíba state, presents expressive difference from the deposits of the typical Maria Farinha Formation, and it could represent another unit. These reefal carbonates was deposited in reef-lagoons complexes and are separated from the Maria Farinha Formation by an unconformity and, probably indicate the establishment of a lowstand system tract. The ichnofacies interpreted for them was Trypanites?. The data integration suggests a paleobathymetry of middle to inner platform (150-80m), for the Gramame Formation, and inner platform to infralitoral $(60-20 \mathrm{~m})$, including proximity of estuaries, for the Maria Farinha Formation.
\end{abstract}

Keywords: Paraiba Basin, ichnofacies, Gramame Formation, Maria Farinha Formation

INTRODUÇ̃̃o A Bacia da Paraíba corresponde à faixa sedimentar costeira compreendida entre a Zona de Cisalhamento de Pernambuco (ZCPE), nas proximidades da cidade de Recife, até o alto de Mamanguape ao norte de João Pessoa (Barbosa et al., 2003) (Figura 1). A bacia corresponde a uma rampa distalmente inclinada que submerge suavemente para leste, em direção ao Oceano Atlântico (Mabesoone \& Alheiros, 1993; Barbosa, 2004; Lima Filho et al., 2005), sendo compartimentada em subbacias ou blocos, limitados por grandes falhas do embasamento Pré-Cambriano no sentido geral E-W e NE. De sul para norte, a Bacia da Paraíba divide-se nas sub-bacias Olinda, Alhandra e Miriri conforme o modelo proposto por Mabesoone \& Alheiros (1988, 1991, 1993) e posteriormente modificado por Barbosa et. al. (2003) (Figura 1).

A Bacia da Paraiba é constituída por cinco unidades litoestratigráficas (Figura 2): Formação Beberibe - arenitos flúviolacustres de idade santoniana?-campaniana? (Beurlen, 1967a, 1967b; 1967c; Mabesoone \& Alheiros, Feijó, 1994; 1993, Souza, 1998); Formação Itamaracá - arenitos calcíferos, folhelhos carbonáticos e calcários com siliciclásticos de idade campaniana-neo-maastrichtiana (Kegel, 1955; Lima Filho et al., 1998; Barbosa et al., 2003; Souza, 1998, 2006); Formação Gramame - calcários, margas e calcários margosos, ricos em micro e ma- crofósseis, depositados em plataforma carbonática média a rasa, de idade maastrichtiana (Maury, 1930; Beurlen, 1967a, 1967b; 1967c; Tinoco, 1971; Muniz, 1993; Lima \& Koutsoukos, 2002); Formação Maria Farinha, definida por duas faciologias distintas, denominadas informalmente por Formação Maria Farinha Inferior e Superior. A inferior corresponde a uma seqüência de calcários argilosos e margas, similares aos depósitos da Formação Gramame, depositados em ambiente de plataforma rasa de idade daniana (Beurlen, 1967a, 1967, 1967c; Muniz, 1993). A Formação Maria Farinha Superior corresponde aos calcários eocênicos recristalizados, dolomíticos, localmente biodetríticos depositados em lagunas costeiras e frentes recifais (Muniz, 1993; Almeida, 2000); e Formação Barreiras - representando depósitos de leques aluviais e fluviais, de idade plio-pleistocênica (Beurlen, 1967a, 1967c; Mabesoone \& Alheiros, 1988, 1993), que ocorrem sobre toda a área da bacia, recobrindo de forma discordante as outras unidades cretáceas e paleogênicas (Figura 2).

Neste trabalho objetivou-se apresentar e discutir uma interpretação paleoambiental das unidades carbonáticas, formações Gramame e Maria Farinha, a partir de investigações icnológicas, sedimentológicas e correlações estratigráficas.

A Formação Gramame representa uma extensa plataforma

1 - PRH-26/ANP/UFPE, Av. Acadêmico Hélio Ramos, s/n, Cid. Univ. 50740-530. barboant@ hotmail.com,

2 - Universidade Estadual do Vale do Acaraú - UVA-CE, Av. da Universidade, 850, Betânia, Sobral. somalia@uvanet.br

3 - DGEO-UFPE, Av. Acadêmico Hélio Ramos, s/n, Cid. Univ. 50740-530, neumann@ufpe.br 


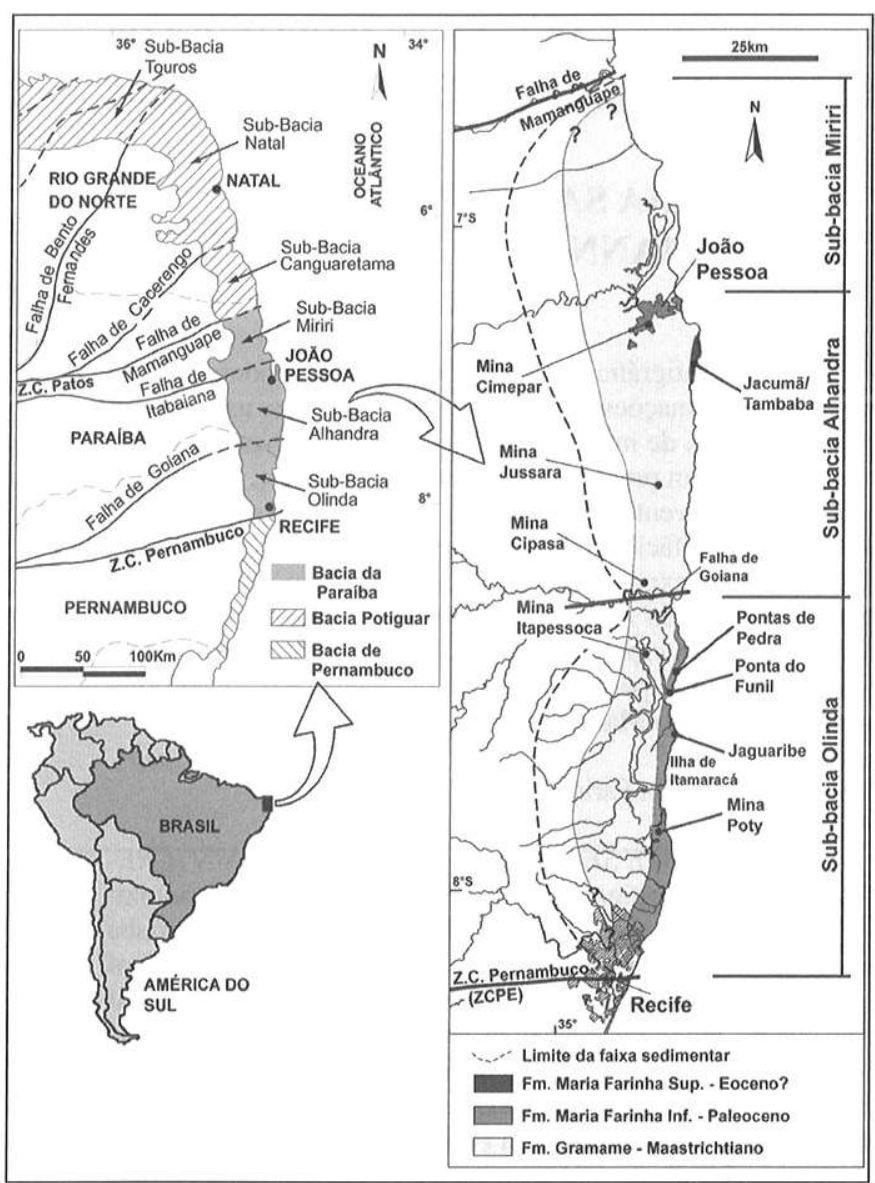

Figura 1-Mapa de localização, extensão e compartimentação da Bacia da Paraiba (Mabesoone \& Alheiros, 1993; Barbosa et al., 2003; Barbosa, 2004; Souza). A distribuição das unidades é mostrada desconsiderando as coberturas do Neogeno. Os pontos pretos indicam os principais afloramentos das unidades Gramame e Maria farinha.

carbonática em forma de rampa que recobriu a plataforma continental durante o Maastrichtiano, sob um regime de mar alto (Barbosa, 2004). Já a Formação Maria Farinha possui extensão reduzida em relação à plataforma Gramame. O registro da Formação Maria Farinha Inferior, de idade paleocênica, ocorre na área emersa da bacia, apenas entre a cidade de Recife e o Alto de Goiana, Sub-bacia Olinda (Figura 1).

Os depósitos que representariam a fácies superior da Formação Maria Farinha, por sua vez, ocorrem de forma restrita na faixa de litoral entre as praias de Jacumã e Tambaba, Sub-bacia Alhandra, ao sul da cidade de João Pessoa, na Paraíba (Figura 1).

METODOLOGIA Dentre os mais importantes locais de afloramentos das unidades Gramame e Maria Farinha (Figura 1), foram escolhidas três localidades-chave para investigações mais extensas, por apresentarem boa exposição contínua, e possibilidade de observação dos estratos em perspectiva 3D. As seções selecionadas foram: as frentes de lavra da mina Poty, localizada em Paulista, Pernambuco; as falésias da Ponta do Funil em Catuama, Pernambuco, e, alguns afloramentos no litoral da Paraíba, entre as praias de Jacumã, Coqueirinho e Tambaba (Figura 1). As localidades da mina Poty e Ponta do Funil apresentam estratos do Maastrichtiano e do Daniano, com seções da passagem Cretáceo-Paleogeno sem descontinuidades. Os afloramentos do litoral da Paraíba apresentam apenas manchas de calcários recifais que ocorrem como bancos isolados em forma de franjas

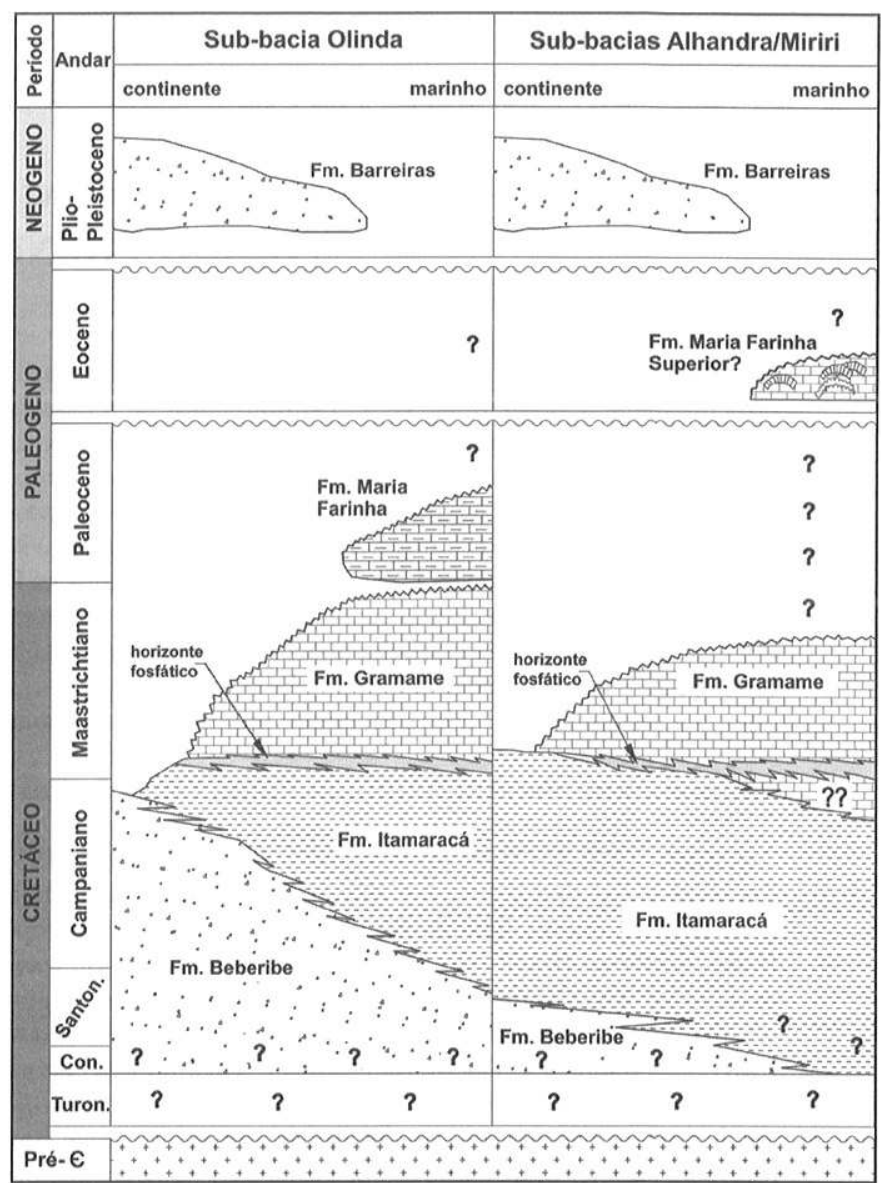

Figura 2 - Carta estratigráfica esquemática da porção emersa da Bacia da Paraíba (modificado de Barbosa et al., 2003; Barbosa, 2004).

(Figura 1). Adicionalmente foram investigados afloramentos da fácies inferior da Formação Maria Farinha nas praias de Jaguaribe e Pontas de Pedra, litoral norte de Pernambuco (Figura 1).

Também foram incluídas observações da unidade Gramame advindas de mapeamento geológico nas minas Itapessoca, CIPASA (Cimento Poty da Paraíba S/A), CIMEPAR (Companhia Paraíba de Cimento Portland) e Jussara, situadas respectivamente na ilha de Itapessoca - PE, Caaporã - PB, João Pessoa - PB e Alhandra - PB (Figura 1).

A base das interpretações foi a observação do conteúdo icnológico das três localidades-chave, integrada a estudos estratigráficos e sedimentológicos a nível faciológico e petrográfico. As etapas metodológicas aplicadas foram: elaboração de perfis estratigráficos e sedimentológicos dos afloramentos, para correlações estratigráficas; detalhamento do conteúdo icnofossilífero, incluindo identificação, registro fotográfico e coleta; amostragem para confecção de lâminas delgadas e integração dos dados para interpretação paleoambiental e icnofaciológica.

Aspectos Sedimentológicos e Paleoambientais da Formação Gramame A deposição da Formação Gramame ocorreu sob o domínio de um trato de mar alto, em condições de relativa calma tectônica, sobre uma plataforma com baixo gradiente (Barbosa, 2004). A partir do Maastrichtiano Superior, instalou-se um evento regressivo que se acentuou no Paleogeno, provavelmente impulsionado por um soerguimento tectônico da bacia (Barbosa, 2004), e que pode ter sido mais intenso em sua região norte, o que pode ter implicado, na exposição e erosão da plataforma carbonática e de prováveis depósitos paleocênicos ausentes nas 
sub-bacias Alhandra e Miriri (Figuras 1 e 2) (Barbosa, 2004; Morais et al., 2004; Morais et al., 2005).

A Formação Gramame exibe uma monótona seqüência de calcários biomicríticos (wackstones/packstones) e margas (mudstones) (Figuras 5a a 5f) que representam repetidos eventos de variação do nível do mar, ciclos de raseamento (shallowstanding upward) de $5^{\text {a }}$ ordem (Figura 3). Os estratos possuem acamamento planar e grande regularidade lateral, demonstrando a atuação predominante de processos de agradação na plataforma carbonática (Figuras 3, 6a e 6b). As microfácies identificadas por esta pesquisa corroboram o que foi descrito por El Gadi \& Broockfield (1999), e por Lima \& Koutsoukos (2004). Os ciclos calcário-marga estariam associados aos ciclos de Milankovich, conforme Schlicht et al. (1999). A alternância destes eventos significaria períodos de maior influxo de argilominerais para dentro da plataforma carbonática quando o clima estava mais úmido, ou maior domínio de carbonatos biogênicos, quando o clima se tornava mais quente e seco, reduzindo o intemperismo (Albertão, 1993; Barbosa, 2004). Estudos mostraram que a porção inferior da Formação Gramame apresenta predominância de montmorilonita (grupo das esmectitas) e de ilita e menor de caulinita (Menor et al., 1977; Menor \& Amaral, 1979).

Os estratos da unidade Gramame exibem finas ondulações argilosas e marcas de retrabalhamento provocadas por correntes de fundo durante tempestades (Figura $6 \mathrm{a}, 6 \mathrm{~b}$ e $6 \mathrm{~g}$ ). Contudo, não ocorre em nenhum afloramento dessa unidade a presença de fluxos de areia ou detritos, sendo rara a presença de grãos siliciclásticos. Não ocorrem estruturas sedimentares indicativas de ondas de bom tempo. A ação das ondas de tempestade resultou no retrabalhamento do substrato, composto predominantemente de lama carbonática, causando a morte dos organismos e o acúmulo de carapaças e conchas formando horizontes de acúmulo, principalmente de restos de moluscos, equinóides e de decápodes formando leitos de conchas (shellbeds) (Barbosa, 2004). Nestes níveis de tempestitos são preservadas espessas tramas horizontais de tubos do icnogênero Thalassinoides Ehrenberg, 1944 (Figura 4, 6b e 6g) que representam icnitos de habitação, Domichnia.

Segundo Brett et al. (1997), os depósitos de leitos de conchas, indicam o processo alternado de retrabalhamento com morte, acúmulo e soterramento, seguido de recolonização, preservando horizontes de acúmulos relativos a cada evento de maior energia. No caso da Formação Gramame, a preservação de carapaças de moluscos e equinóides em posição de vida e com baixo grau de desarticulação e fragmentação indica que a maioria foi soterrada em posição de vida dentro do substrato mole, e uma parte menor foi carregada, acumulada e soterrada de forma repentina, e rápida, com pouco transporte (Barbosa, 2004). Aspecto semelhante foi observado para concentrações de carapaças de crustáceos decápodes em estratos da Formação Maria Farinha na mina Poty (Távora \& Miranda, 2004).

A abundância de organismos infaunísticos, nos estratos do Maastrichtiano Médio e Superior, principalmente de calianassídeos e equinóides irregulares, escavadores de substrato macio, sugere substrato não consolidado, composto essencialmente por lama carbonática, constantemente bioturbado. A ocorrência de pirita verificada nas camadas margosas e nos calcários (Figuras $5 \mathrm{a}, 5 \mathrm{~b}$ e $5 \mathrm{f}$ ), pode indicar um soterramento de matéria orgânica durante eventos episódicos de alta energia. O reconhecimento de pirita dentro de tubos de Thalassinoides, pode indicar o soterramento de matéria orgânica dentro das galerias, e instalação de microambientes anóxicos ou com baixa oxigenação. Também é comum a ocorrência de glauconita preenchendo carapaças de foraminíferos e cistos de calcisferas (Figuras 5a, 5c e 5d), cuja origem pode estar relacionada com processos diagenéticos tardios. Os calcários da Formação Gramame apresentam níveis dolomitizados, possivelmente associados à ação de diagênese tardia, devido à proximidade da atual zona de litoral, que favoreceu a circulação de água meteórica (Figuras 5e e 5f).

Aspectos Sedimentológicos e Paleoambientais da Formação Maria Farinha A Formação Maria Farinha possui uma ocorrência complexa, devido aos eventos ocorridos a partir do final do Cretáceo e durante o Paleogeno (Figura 1). Na mina Poty, verifica-se após a passagem K-T uma gradual transição dos carbonatos para margas e por fim um maior influxo de elementos siliciclásticos. Os estratos do Paleoceno nesta localidade compreendem cerca de $15 \mathrm{~m}$ de espessura, e apresentam semelhanças litológicas e icnológicas com os estratos da Formação Gramame, sendo que na Formação Maria Farinha as camadas de marga são mais espessas, e foram depositadas em ambiente carbonático, com grande influxo de argilas (Figuras 6c e 6d). A análise mineralógica da Formação Maria Farinha, na sub-bacia Olinda, revelou uma predominância de esmectita (65 a 90\%) com ocorrência de caulinita (10 a 25\%) e menor influência de ilita $(<10 \%)$ (Menor \& Boujo, 2000).

O importante influxo de argila, a abundância de crustáceos decápodes e de moluscos ostreídeos levou Beurlen (1967a, 1967b) a associar estes estratos com depósitos de mangues/planícies de maré ou com proximidade de estuários (Figuras 6c e 6d). Silva et al. (2001) identificaram nos estratos paleocênicos da mina Poty, em Pernambuco, uma fauna de vertebrados contendo peixes ósseos, seláquios (raias e tubarões), e répteis (tartarugas e crocodilo marinho). Os autores consideraram que a fauna indica um ambiente de águas costeiras rasas, com habitantes de recifes de corais e costas rochosas, que usariam as zonas de estuários para alimentação e reprodução.

Os calcários depositados imediatamente após a passagem Cretáceo-Paleogeno, que correspondem a Formação Maria Farinha Inferior, incluem bioesparitos dolomitizados, com maior quantidade de terrígenos do que os calcários da Formação Gramame (Figuras 7a a 7f), bem como há maior abundância de foraminíferos bentônicos, fragmentos de ostreídeos e ossos de peixes fosfatizados e piritizados (Fig. 7e - 7f). De uma forma geral, as microfácies encontradas indicam incremento de uma regressão marinha com maior aporte de siliciclastos (Albertão, 1993; Barbosa, 2004).

Os calcários paleocênicos aflorantes nas praias de Jaguaribe, Pontas de Pedra e Ponta do Funil (Figura 1), no litoral de Pernambuco (Sub-bacia Olinda), exibem semelhança faciológica com a Formação Maria Farinha Inferior, representada na mina Poty. Todas estas ocorrências estão próximas à atual linha de costa e evidenciam a regressão do mar Gramame, que, provavelmente, expôs parte da sua plataforma carbonática à erosão e fez progradar a paleolinha de costa, trazendo condições de deposição cada vez mais rasas (Figuras 1 e 2).

Estes calcários, que ocorrem no litoral norte de Pernambuco, no flanco norte da Sub-bacia Olinda (Figura 1), apresentam moldes de conchas de moluscos, pequenos corais hermatípicos solitários, dentes de seláquios, fragmentos de equinóides e estruturas sedimentares indicativas de ondas de bom tempo em lagunas costeiras ou plataforma muito rasa com influxo de lama. Tais depósitos representam uma transição ou intercalação de fácies desta unidade que foi depositada em ambiente cada vez mais raso, à medida que se deslocava em direção ao flanco norte da Sub-bacia Olinda. Estes depósitos da Formação Maria Farinha, que ocorrem em praias, ao norte de Itamaracá, em direção ao Alto de Goiana (Figura 1), testemunham maior ação regressiva, mas ainda se mostram associados à Formação Maria Farinha Inferior, nos seus aspectos faciológicos e icnológicos.

Formação Maria Farinha Superior? Como citado anterior- 


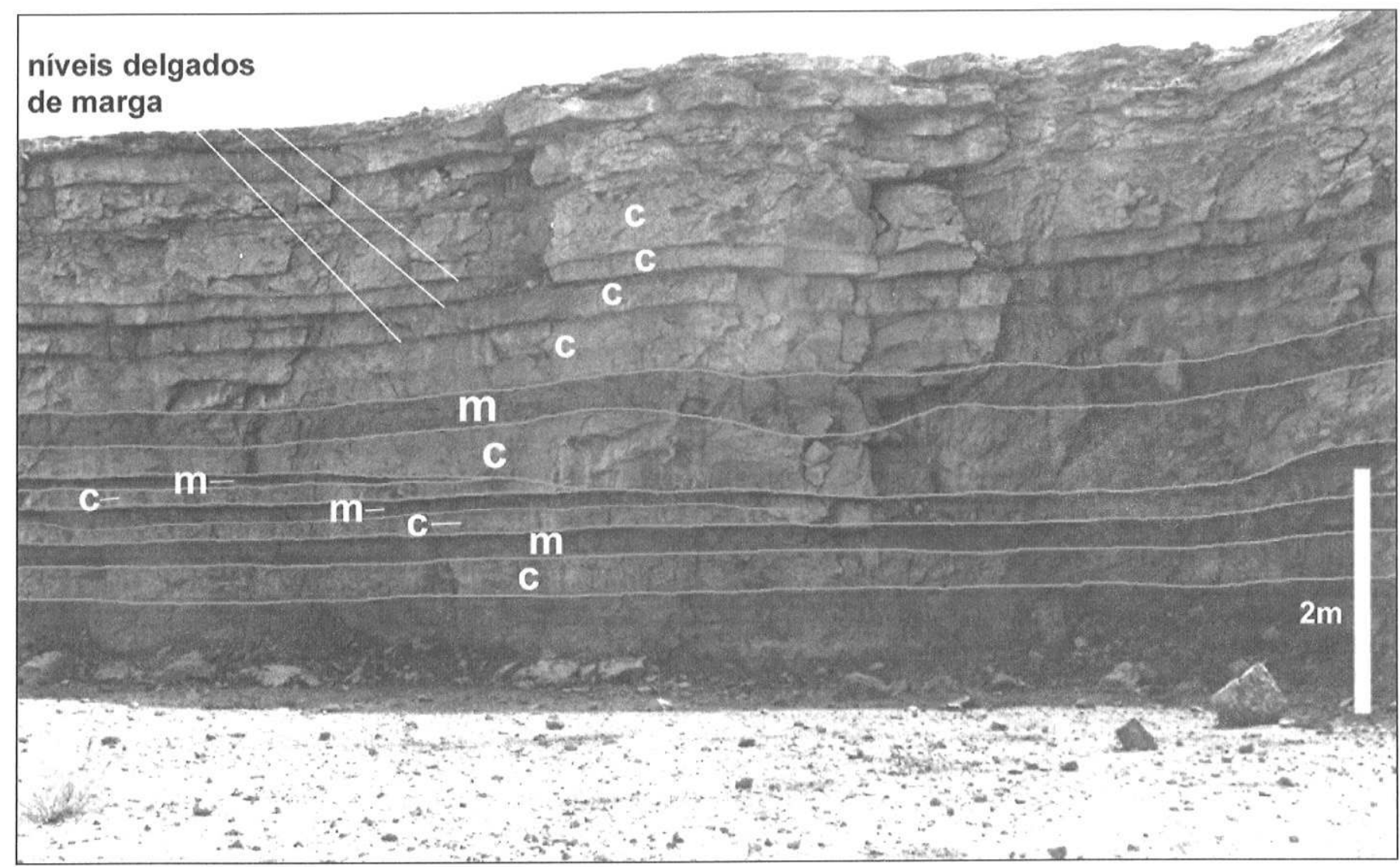

Figura 3 - Depósitos da Formação Gramame (Maastrichtiano) na Mina CIPASA, em Caaporã, Paraiba. Ciclos de margas (m) e calcários (c).

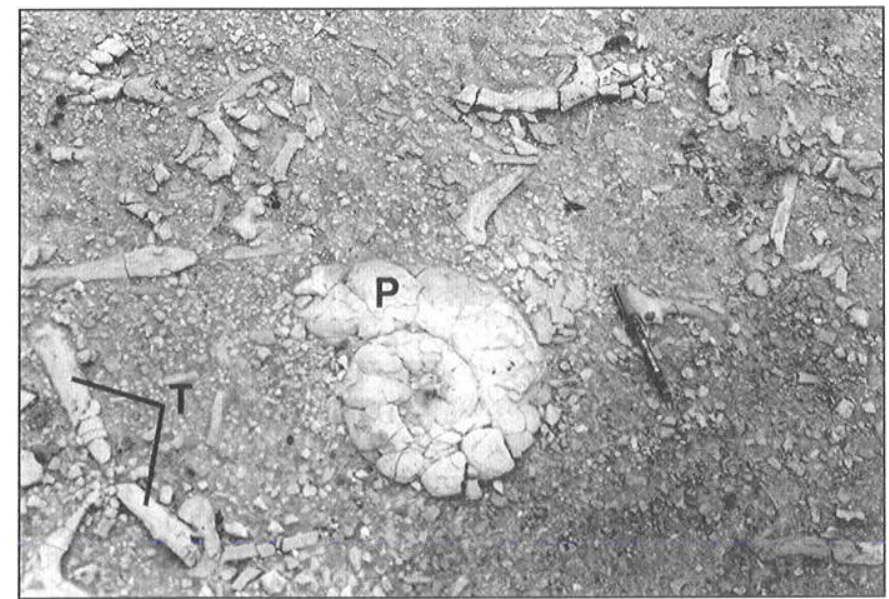

Figura 4 - Pavimento de bancada na Mina CIMEPAR, em João Pessoa, Paraíba, com preservação de tramas de tubos Thalassinoides Ehrenberg, 1944 (T), e restos de carapaças, incluindo um molde de carapaça de amonóide Pachydiscus (P).

mente, ocorrem na região costeira do Estado da Paraíba afloramentos de calcários recifais atribuídos a Formação Maria Farinha (Beurlen, 1967a, 1967b; Oliveira, 1978; Almeida, 2000) (Figura 1). Entretanto, a sua paleofauna, litofaciologia e correspondente ambiente deposicional, distinguem-se das características observadas na seção da mesma unidade litoestratigráfica encontrada na mina Poty, em afloramentos de praias e em poços na sub-bacia Olinda (Barbosa et al., 2003; Barbosa, 2004).

Segundo Almeida (2000) este conjunto litológico foi depo- sitado em ambientes de frente recifal, núcleo recifal e recifal-lagunar, discutindo a necessidade de integração entre a faciologia verificada nesses afloramentos e a faciologia típica da Formação Maria Farinha verificada na Sub-bacia Olinda, sugerindo uma possível discordância entre os dois registros. O autor atribuiu uma idade eocênica para os calcários recifais, baseado principalmente na malacofauna.

A ocorrência irregular destes depósitos paleogênicos indica a ação diferenciada do evento regressivo de sul para norte, tornando-se mais intenso entre o Alto de Goiana e o norte de João Pessoa (Sub-bacias Alhandra e Miriri). É possível que os depósitos descritos por Almeida (2000) representem uma parada do nível do mar após o evento regressivo, no Eoceno, possibilitando a deposição de franjas de calcários recifais e lagunas costeiras. É provável que as diferentes litofácies da Formação Maria Farinha representem diferentes estágios de pulsos regressivos influenciados pela ação de eventos tectônicos, nas sub-bacias da Bacia da Paraíba, que ocorreram a partir do final do Cretáceo e, principalmente, durante o Paleogeno (Barbosa, 2004; Morais et al., 2004; Morais et al., 2005). A ocorrência de patamares de depósitos durante eventos regressivos foi descrita por Hunt \& Tucker (1992) como um possível efeito da parada na progradação de regressões forçadas (forced regressive wedge systems), onde cada depósito autóctone representaria um registro do pulso regressivo (falling stages), e a parada no nível mais baixo indicaria um limite de seqüência. Segundo Hunt \& Tucker (1992), em ambientes carbonáticos estes depósitos irão consistir tipicamente em grainstones e recifes de coral.

Os calcários encontrados na região litorânea entre Jacumã e Tambaba compõe-se principalmente de esparitos e microesparitos, recristalizados com dolomita (Figuras 8a e 8b), bioesparitos e dismicritos com porosidade vugular devido à dissolução de 

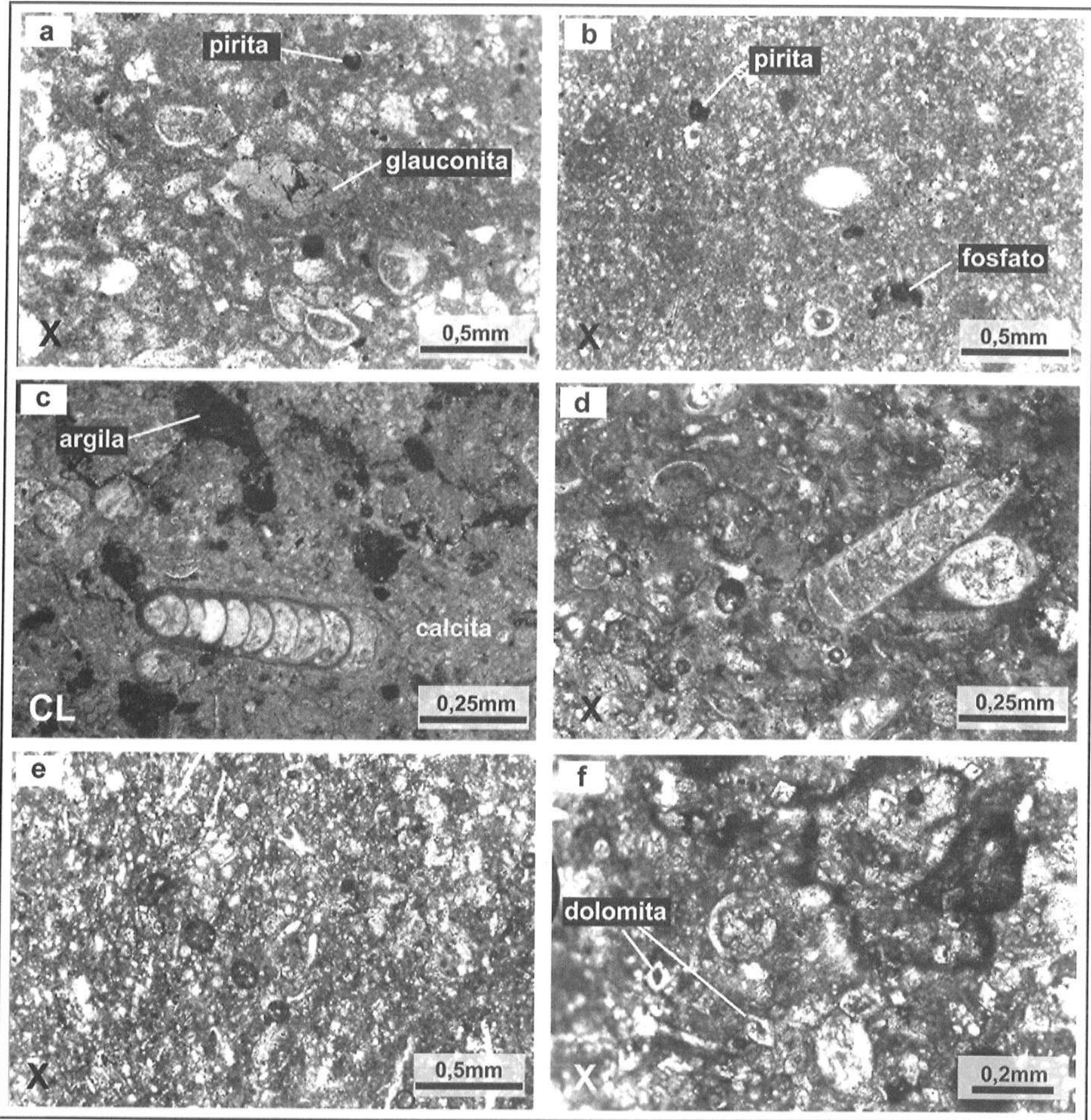

Figura 5 - Fotomicrografias da Formação Gramame. a) bioesparito com carapaças de foraminiferos preenchidas por glauconita (mina Poty, Pernambuco); b) biomicrito com carapaças de ostracodes, fragmentos de ossos de peixes fosfatizados, e pellets piritizados (mina Poty, Pernambuco); c-d) bioesparitos com laminações de argila (mina Itapessoca, Pernambuco); e-f) bioesparitos com cristais de dolomita e pirita (mina Jussara, Paraíba). $(X=$ nicóis cruzados; $C L=$ catodoluminescência)

conchas de moluscos, fragmentos algálicos e de corais (Figuras 8c e 8d). Há níveis compostos por calcários micríticos recristalizados com laminações algálicas, cujas estruturas foram substituídas por calcita espática e dolomita. Estes depósitos apresentam abundantes moldes de conchas com perfurações construídas por esponjas e moluscos (Fig 8e e 8f). Ocorrem também calcários recifais com abundante conteúdo de restos de algas calcárias com grande porosidade inter e intraparticula (Fig. $8 \mathrm{~g}$ e $8 \mathrm{~h}$ ).

A existência de leitos de bioclastos com efeito de bioerosão é indicativa de períodos de baixa taxa de sedimentação, águas claras e rasas com baixa a moderada energia, onde se desenvol- veu a colonização destes leitos pelos organismos incrustantes e perfuradores (Frey \& Pemberton, 1984; Pemberton \& MacEachern, 1995). Componentes de substratos duros como conchas seriam rapidamente fragmentadas em ambientes de alta energia ou soterradas em ambientes com altas taxas de sedimentação, por isso as comunidades colonizadoras de substratos duros possuem condições limitadas de oportunidades (Taylor \& Wilson, 2003). O acúmulo de cimento no espaço poroso e o concomitante endurecimento do substrato, cria a superfície endurecida, isto faz cessar os processos de bioturbação que são substituídos pelos processos de bioerosão (Bromley, 1990). Segundo 


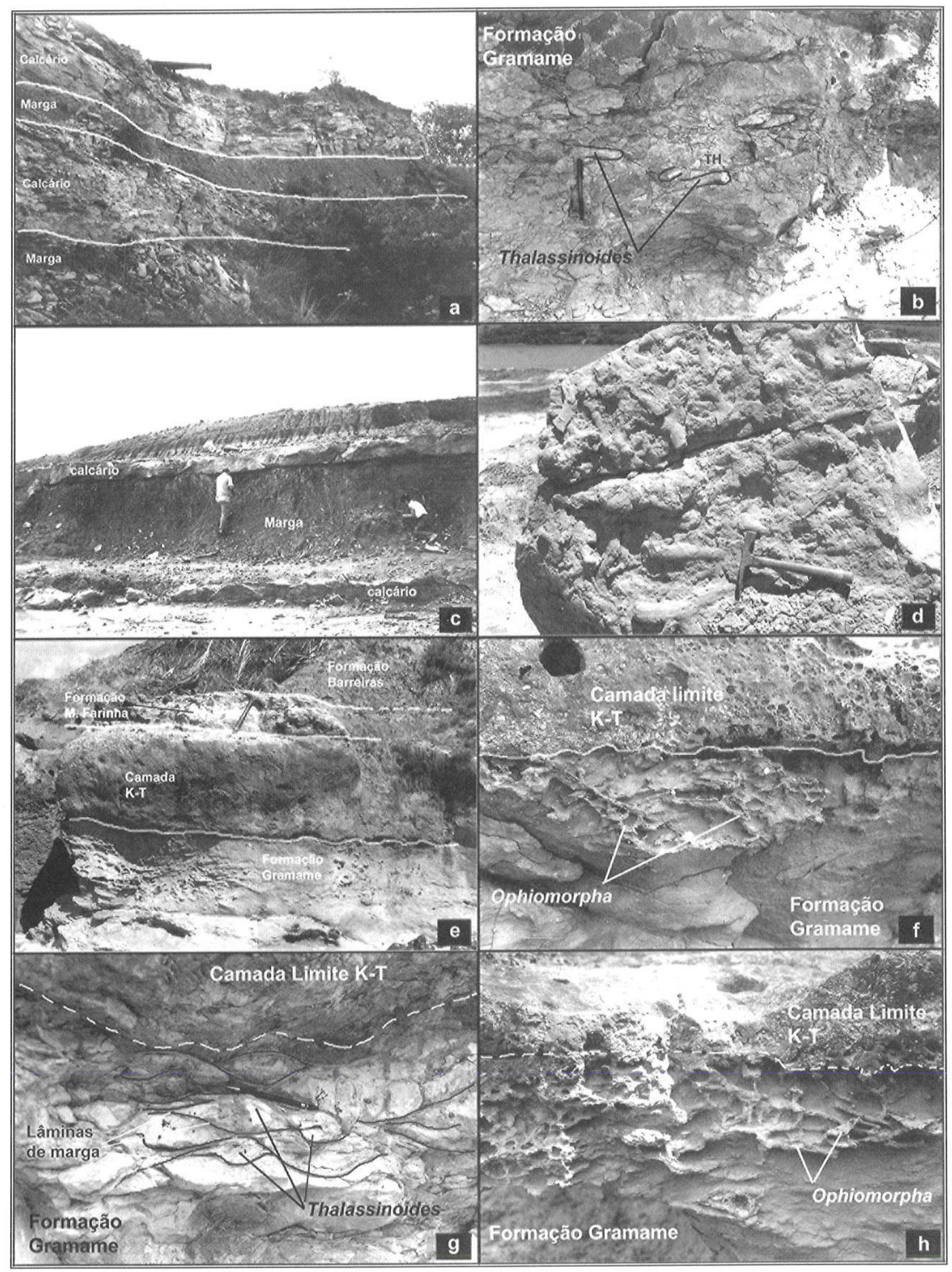

Figura 6 - a) Depósitos da Formação Gramame com camadas de calcário e marga representando ciclos de raseamento - shallowstanding upward, mina Poty, Pernambuco; b) detalhe das camadas abaixo da passagem K-T, mina Poty; c) estratos da Formação M. Farinha 6m acima da Passagem K-T na mina Poty, mostrando o espessamento das camadas de marga; d) detalhe da base de uma camada de calcário da F. Maria Farinha exibindo tramas de Thalassinoides Ehrenberg, 1944, mina Poty; e) topo da Formação Gramame imediatamente antes do limite K-T, Ponta do Funil, Pernambuco; f) topo da Formação Gramame na Ponta do Funil com tramas de tubos de Ophiomorpha nodosa Lundgren, 1891, e planos de erosão provocados por ondas de bom tempo; g) detalhe do topo da Formação Gramame, imediatamente antes da Passagem K-T na mina Poty com tubos de Thalassinoides (TH); $h$ ) detalhe do topo da Formação Gramame antes da passagem K-T na Ponta do Funil, exibindo tramas de tubos de O. nodosa Lundgren, 1891. 


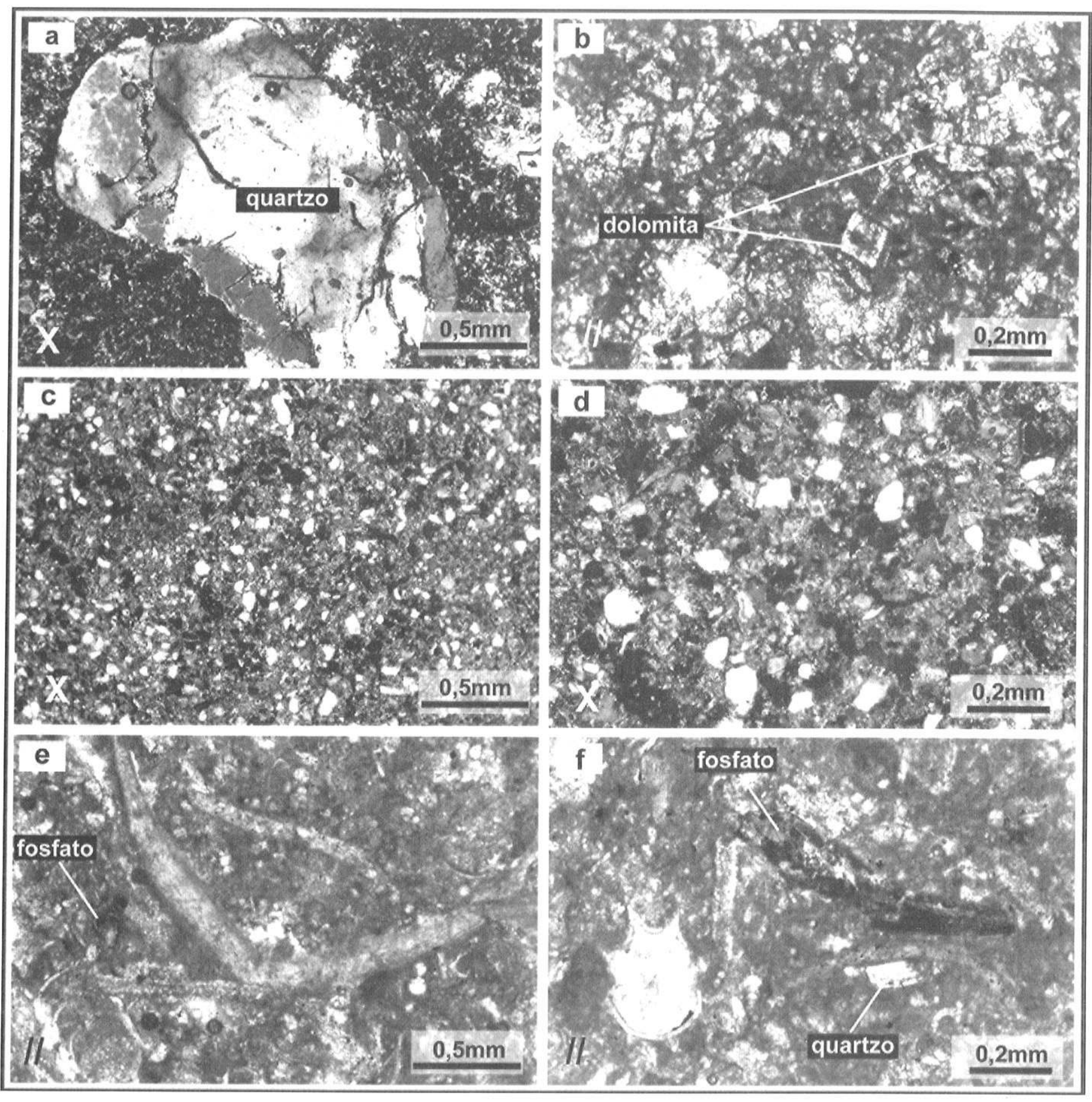

Figura 7-Micrografias da Formação Maria Farinha Inferior. a) doloesparito com abundante pirita e cristais de quartzo (Ponta do Funil, Pernambuco); b) bioesparito com presença de quartzo e cristais de dolomita (Ponta do Funil); c-d) marga rica em quartzo (mina Poty, Pernambuco); e-f) bioesparito cl fragmentos de ossos de peixe fosfatizados, restos de decápodes e equinóides (Pontas de Pedra, Pernambuco) ( $X$ = nicóis cruzados; // = nicóis paralelos).

Bromley (1994), em contraste com icnofósseis produzidos em substrato macio, os padrões de comportamento refletidos por bioerosão são mais limitados, sendo dominados por icnitos de habitação (Domichnia).

A existência de substrato carbonático consolidado pode representar períodos de hiato sedimentar, baixa taxa de sedimentação e compactação, que resultam em superfícies de descontinuidade do registro (Frey \& Pemberton, 1984). Segundo Pemberton e MacEachern (1995), a erosão provocada por tratos de mar baixo tipicamente produz uma difusão generalizada de superfícies de substrato duro (woodgrounds, firmgrounds e hardgrounds).
Nos estratos estudados é possível observar a repetição de níveis de leitos de conchas e fragmentos de corais onde se desenvolveu a bioerosão, alternado com níveis de crescimento de corais e algas, o que indica sucessivos períodos de formação destes leitos e posterior período de colonização, formando hardgrounds intercalados na sucessão.

Icnofácies - Formação Gramame Segundo Muniz (1993), os calcários da Formação Gramame foram depositados em área de plataforma externa, a partir do registro icnofossilífero que define a icnofácies Cruziana, considerando uma distribuição mais 
distal para Thalassinoides.

Trabalhos anteriores, com foraminíferos (Tinoco, 1971), integração de foraminíferos e palinomorfos (Albertão, 1993) e ostracodes (Fauth \& Koutsoukos, 2002), sugeriram uma batimetria correspondente a plataforma aberta à batial para a Formação Gramame, e de plataforma interna para a Formação Maria Farinha. Contudo, as observações realizadas recentemente (Barbosa et al., 2003; Barbosa, 2004), mostraram que o processo de regressão ocorrido na bacia, pode ter gerado diferentes ambientes, em estágios diferentes da regressão o que implicou na existência de um complexo registro estratigráfico, sedimentológico e paleontológico, para os depósitos do Maastrichtiano Superior e para os depósitos do Paleoceno-Eoceno?.

Os estratos da Formação Gramame nos afloramentos mais representativos, ao longo de toda a faixa costeira, exibem uma baixa diversidade de icnofósseis, sendo mais abundante o icnogênero Thalassinoides Erhenberg, 1944 (Fig. 6b, 6d, 6g e 9e). As tramas de galerias ocorrem preservadas, tanto nas camadas calcárias, quanto nos níveis margosos de tempestitos (Figuras $6 \mathrm{a}, 6 \mathrm{~b}, 6 \mathrm{c}, 6 \mathrm{~d}$ e $9 \mathrm{e})$.

Os depósitos que correspondem ao Maastrichtiano Médio e Superior apresentam características muito semelhantes ao longo de toda faixa costeira (Figuras 3, 6a e 6b), e são comumente abundantes em restos de calianassídeos e equinóides, bem como dentes de seláquios. Nestes depósitos foram reconhecidos os icnogêneros Palaeophycus Hall, 1847 (Figura 9a), Planolites Nicholson, 1973 (Figuras 9b e 9e), e Gyrolithes De Saporta, 1884 (Figura 9c), normalmente atribuído a crustáceos calianassídeos e talinassídeos (Buatois et al., 2002; Fernandes et al., 2002). No entanto, a maior abundância é de tramas de galerias do icnogênero Thalassinoides (Figuras 9d e 9e). A presença abundante de Thalassinoides em todos os estratos do Maastrichtiano, juntamente com os restos de calianassídeos, mostra que durante todo o período de deposição, as condições ambientais favoreceram a permanência destes animais, e a construção de tramas de galerias.

As galerias de Thalassinoides apresentam-se arredondadas a ovaladas, com dimensões variadas, cujas seções variam de 1,5 até $4 \mathrm{~cm}$ de diâmetro, preservadas tridimensionalmente, em estratos margosos de tempestitos, possivelmente preenchidas por soterramento, devido à agitação provocada por ondas de tempestade. Níveis de galerias se sobrepõem uns sobre os outros nos horizontes de tempestitos, mostrando a retomada de sua construção após cada evento de agitação do fundo em períodos nos quais estes foram mais freqüentes. As tramas horizontais exibem características bifurcações em "Y" ou em "T" de Thalassinoides, cujas paredes dos tubos são localmente ornamentadas por estrias (Figuras 9d e 9e).

A única ocorrência de Gyrolithes foi encontrada nos estratos do Maastrichtiano Médio, na Sub-bacia Alhandra, em afloramentos da mina Jussara (Figura 1). Esta ocorrência apresenta uma volta com cerca de $6 \mathrm{~cm}$ de diâmetro, tubo cilíndrico, liso com cerca de $1 \mathrm{~cm}$ de diâmetro (Figura 9c). Pemberton \& MacEachern (1997) apontaram que a ocorrência dos icnogêneros Thalassinoides e Gyrolithes, associados, indicam a ação de decápodes em ambientes com deficiência de oxigenação e são indícios de condições ambientais neríticas.

O icnogênero Planolites ocorre em todos os estratos do Maastrichtiano (Figuras 9a, 9e e 9f). Representam escavações de pequeno diâmetro $(0,5$ a $1,5 \mathrm{~cm})$, com seções elípticas devido à compactação. O icnogênero Palaeophycus, é um pouco menos abundante do que Planolites, mais freqüente no Maastrichtiano Médio das Sub-bacias Alhandra e Miriri. Neste caso as escavações com seções que variam de 1 a $2,5 \mathrm{~cm}$, são horizontais e raramente inclinadas em relação à estratificação (Figura 9a).

As condições de deposição juntamente com estas associa- ções icnofóssilíferas permaneceram as mesmas, até o topo da Formação Gramame, como foi possível verificar tanto em superfície quanto em subsuperfície. Na mina Poty, antes da passagem K-T, no topo do Maastrichtiano, tramas de Thalassinoides são abundantes, e o domínio das escavações é horizontal (Figuras $6 \mathrm{~b}$ e $\mathrm{g} 6$ ).

A interpretação desta pesquisa é de que a icnofácies dominante nestes estratos, levando-se em conta os aspectos sedimentológicos e faciológicos, seria Cruziana, dominante nesta faixa da plataforma carbonática ao longo de todo o Maastrichtiano, corroborando a interpretação de Muniz (1993).

Nos estratos da Formação Gramame na Ponta do Funil, cerca de seis metros abaixo da passagem K-T, os calcários são dominados por tramas horizontais de Thalassinoides sp. e de Planolites sp. (Figura 9f). Contudo, observou-se que o topo da formação Gramame na Ponta do Funil (Figura 1), ao contrário do que é verificado nos demais afloramentos ao longo da bacia, apresenta características diferentes da icnofácies Cruziana. Aqui, foi verificado que nos últimos cinco metros do Maastrichtiano ocorre a substituição de Thalassinoides, por Ophiomorpha nodosa Lundgren, 1891 (Figuras 6e, 6f e 6h). Também foi reconhecido no topo da Formação Gramame, a presença local de Skolithos sp. e Planolites sp.

Também, na Ponta do Funil, nos estratos que antecedem a passagem K-T ocorrem estratificações geradas por ondas de bom tempo. As escavações são verticais e sub-horizontais, sendo também comuns estruturas de escape e ajuste da escavação, indicando a ação de ondas e constante agitação do fundo (Figuras $6 \mathrm{e}, 6 \mathrm{f}$ e $6 \mathrm{~h})$. Localmente as tramas de galerias são interrompidas por superfícies de erosão

A substituição de Thalassinoides por Ophiomorpha, neste local, sugere que o ambiente mudou rapidamente forçando os calianassídeos a construírem as galerias em tramas verticais a sub-verticais, enquanto que na Mina Poty, o topo da Formação Gramame, antes da Passagem K-T exibe apenas tramas horizontais de Thalassinoides, dentro da icnofácies Cruziana. Assim, na região da Ponta do Funil, o topo da Formação Gramame, foi depositado sob o domínio da icnofácies Skolithos, constituindo o registro mais raso desta unidade na bacia, até então verificado (Figuras 6e, 6f e 6h).

A icnofácies Skolithos foi sugerida de acordo com as observações sedimentológicas e faciológicas reunidas. Além disso é presumível que uma variação do nível do mar mais abrupta, talvez uma queda do nível eustático de terceira ordem em resposta a uma regressão forçada (Hunt \& Tucker, 1992), levando a condições mais rasas, acarretaria uma mudança no comportamento dos organismos geradores causando uma superposição ou variação lateral para a icnofácies Skolithos (Pemberton \& MacEachern, 1995). A icnofácies Cruziana pode abranger desde regiões plataformais, Cruziana distal, até áreas próximas do litoral, Cruziana proximal, onde pode ocorrer uma transição para a icnofácies Skolithos (Pemberton \& MacEachern, 1995). A transição de ambientes, passando de condições de plataforma para condições próximas de litoral, com a gradual substituição de associações Thalassinoides/Planolites ou de Thalassinoides/ Chondrites por Ophiomorpha é descrita por vários autores (Frey \& Pemberton, 1984; Scasso et al., 1991; Brian et al., 1998; Buatois et al., 2002; Malpas et al., 2005), com o conseqüente aumento de energia no ambiente, que se desloca da zona de ação de ondas de tempestade para o alcance das ondas de bom tempo. Nestes casos há uma transição da icnofácies Cruziana para a icnofácies Skolithos, com o predomínio de Ophiomorpha. A dominância do icnogênero Ophiomorpha na icnofácies Skolithos em estratos mesozóicos, em relação à dominância do icnogênero Skolithos na mesma icnofácies em depósitos paleozóicos pode ser atribuída à grande radiação mesozóica dos crustáceos 


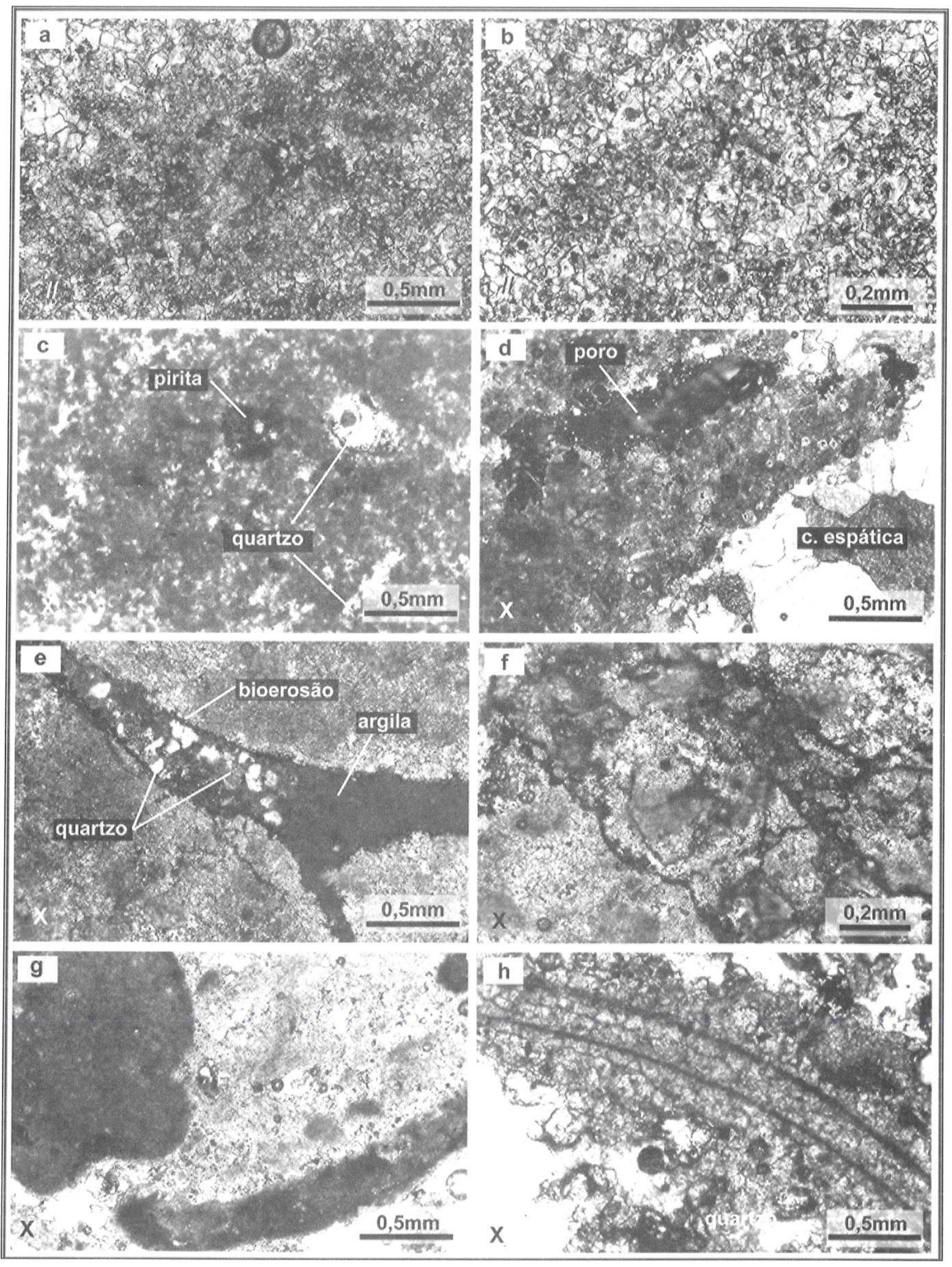

Figura 8 - Micrografias da Formação Maria Farinha Superior?. a-b) esparitos recristalizados dolomíticos (praia de Jacumã, Paraiba); c-d) bioesparitos com calcita espática blocosa, porosidade vugular e cristais de dolomita (praia de Tabatinga, Paraíba); e-f) micritos com perfurações de esponjas (bioerosão) e laminações algálicas (praia de Coqueirinho, Paraiba); g-h) bioesparitos de origem recifal (grainstones/boundstones) compostos, principalmente, por restos de algas calcárias com alta porosidade inter e intraparticula (praia de Tambaba, Paraiba). ( $X$ = nicóis cruzados; // = nicóis paralelos). 


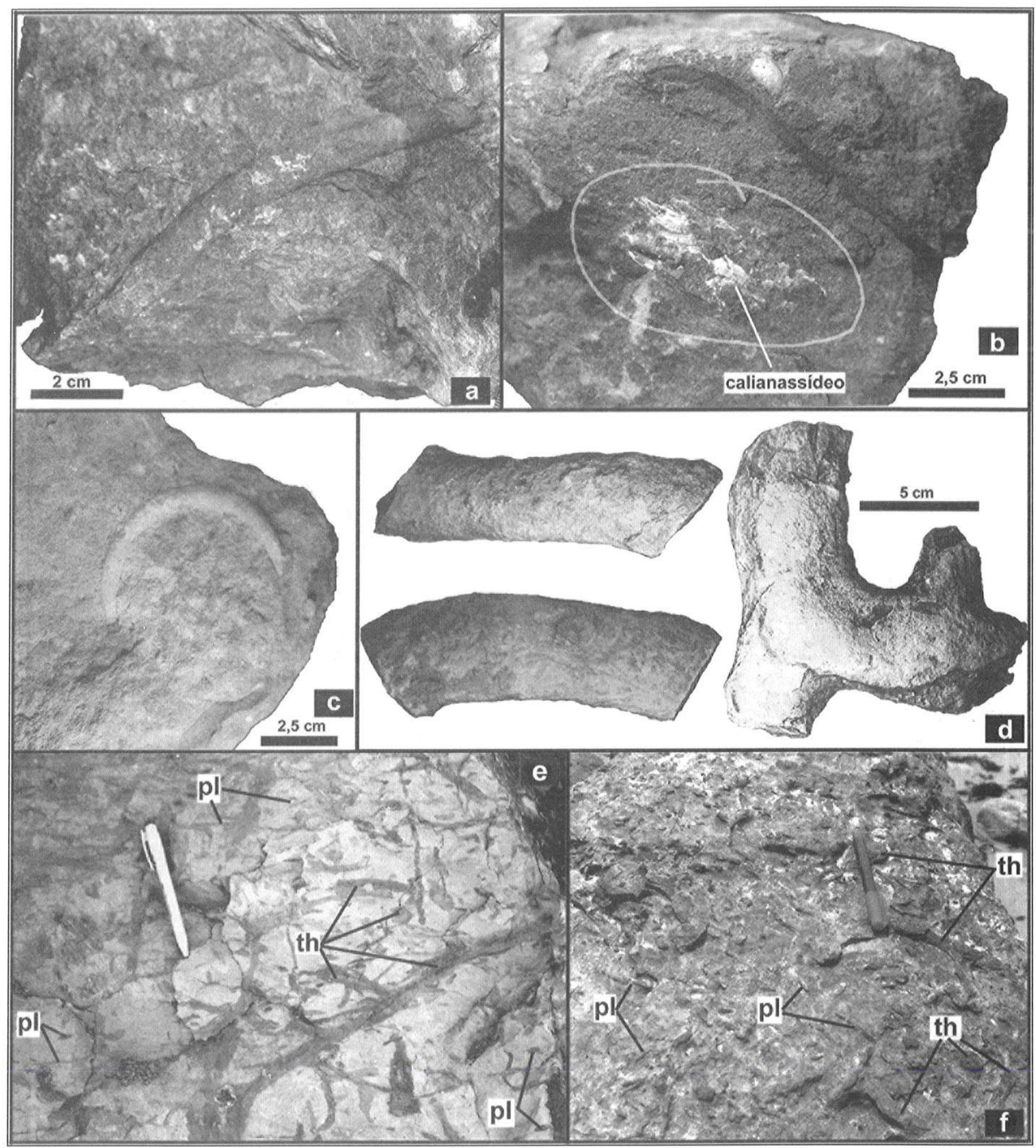

Figura 9-Icnofósseis da Formação Gramame (Maastrichtiano Médio e Superior). a) Palaeophycus? Hall, 1847 (mina CIMEPAR, João Pessoa, Paraiba). b) Planolites? Nicholson, 1873. No detalhe aparecem restos de calianassídeo (mina CIPASA, Caaporã, Paraíba). c) Gyrolithes De Saporta, 1884 (mina Jussara-1, Alhandra, Paraíba). d) Thalassinoides Erhenberg, 1944 (minas Poty e Itapessoca, Pernambuco). e) afloramento da Formação Gramame na mina Jussara-1, Alhandra, Paraíba, com a predominância de Thalassinoides sp. (th) e de Planolites sp. (pl). f) afloramentos da Formação M. Farinha na Ponta do funil, Pernambuco, 6 metros abaixo da passagem $K-T$, onde também predominam Thalassinoides sp. (th) e Planolites sp (pl).

decápodes (Buatois et al., 2002).

Fernandes et al. (2002) comentaram que dependendo do comportamento e do substrato os organismos produtores, neste caso os crustáceos decápodes, podem produzir icnofósseis de gêneros diferentes como, por exemplo, Thalassinoides em fundo lamoso, e Ophiomorpha em substrato arenoso. Este caso verificado na Formação Gramame é um exemplo de tal ação. Ao habitar ambiente mais agitado e com substrato menos estável, os calianassídeos passaram de um icnogênero para outro (Frey \& Pemberton, 1984; Scasso et al., 1991; Brian et al., 1998; Buatois 
et al., 2002; Malpas et al., 2005).

Botjer \& Droser (1994) estudaram a distribuição de Ophiomorpha ao longo de sua evolução mesozóica, visto que as primeiras ocorrências datam do Permiano Inferior. Este icnogênero está intimamente associado a condições de proximidade de áreas litorâneas, complexos estuarinos e deltas, com substratos arenosos, e normalmente associado a icnofácies Skolithos (Botjer \& Droser 1994; Brian et al., 1998). Devido ao fato de Ophiomorpha ser sensível à estabilidade e natureza do substrato, a variação de energia e taxa de sedimentação, o seu padrão geométrico e sua distribuição pode servir como uma valiosa ferramenta icnológica para detectar súbitas mudanças ambientais (Brian et al., 1998). Além disso, Ophiomorpha é mais abundante durante o domínio de tratos de mar baixo, quando fácies marinhas marginais se tornam abundantes (Brian et al., 1998). Pemberton \& MacEachern (1997) afirmaram que a presença de Ophiomorpha e Skolithos é um indicador de ambientes marinhos costeiros instáveis, com alto estresse ambiental, normalmente, características da icnofácies Skolithos.

Pelo exposto, esta ocorrência mais rasa da Formação Gramame, representa uma variação lateral antes não reconhecida, visto que ocorre mudança de icnofácies. Esta hipótese é apoiada pelo fato de que, a Ponta do Funil está localizada no flanco norte da Sub-bacia Olinda (Figura 1), próxima ao Alto de Goiana, o que pode ter significado, condições mais rasas de deposição, contemporâneas às condições mais profundas, verificadas na mina Poty, que estava mais ao sul sobre o depocentro da Subbacia (Figura 1). Neste caso a icnofácies Cruziana sugere uma possível paleobatimetria de plataforma intermediária a interna para toda a rampa carbonática, durante o Maastrichtiano, variando com a fisiografia da bacia $(150-80 \mathrm{~m}$ ? de profundidade). Também ocorreram variações laterais de fácies, entre as icnofácies Cruziana e Skolithos, esta última correspondendo a condições de plataforma interna, rasa, com proximidade litorânea (60 -20 ? $\mathrm{m}$ de profundidade).

Icnofácies - Formação Maria Farinha Inferior Muniz \& Ramirez (1977) atribuíram aos depósitos da Formação Maria Farinha, em Pernambuco, a icnofácies Cruziana, baseando-se principalmente na presença do icnogênero Thalassinoides. Os autores basearam suas conclusões, principalmente, em observações realizadas na seqüência da mina Poty, onde estratos da Formação Maria Farinha (Paleoceno), ocorrem de forma contínua a partir da passagem K-T (Figuras 6c e 6d). Os autores concluíram que os dados icnológicos apurados sugeriam a deposição da unidade em ambiente sublitoral raso, de energia moderada a relativamente baixa. Porém, vários aspectos precisam ser considerados em relação à sugestão da icnofácies Cruziana para os estratos paleocênicos da Formação Maria Farinha que ocorrem no norte da Sub-bacia Olinda.

De acordo com a avaliação do presente trabalho, na mina Poty, os estratos da Formação Maria Farinha apresentam uma litofaciologia semelhante aos calcários e margas correspondentes à Formação Gramame. Como sugeriram Muniz \& Ramirez (1977), estes estratos correspondem à icnofácies Cruziana, também sugerida aqui para a Formação Gramame. Contudo, a pesquisa observou condições faciológicas e icnológicas diferentes em afloramentos de carbonatos da Formação Maria Farinha Inferior, que ocorrem nas praias de Ponta do Funil, Jaguaribe e Ponta de Pedras (Figura 1). Nestas praias a Formação Maria Farinha que sucede a passagem K-T, Formação Maria Farinha Inferior, apresenta indícios de deposição rasa, sob condições de plataforma interna a sublitoral. Foram encontrados calcários detríticos conchíferos com grande aporte siliciclástico, observado em lâminas delgadas (Fig. 7a, 7b, 7e e 7f), aspectos estes, que não ocorrem na Formação Maria Farinha Inferior depositada na região da mina Poty. A pesquisa verificou a presença dos icnogêneros Thalassinoides Erhenberg, 1944, Ophiomorpha nodosa Lundgren, 1891, Planolites Nicholson, 1873 e de Skolithos Haldemann, 1840, nestes afloramentos. O icnogênero Ophiomorpha ocorre na forma de tramas sucessivas tornando-se cada vez mais abundante em direção ao topo destes depósitos. Muitas das galerias preservadas estão preenchidas por material detrítico, possivelmente transportado durante eventos de alta energia.

Malpas et al. (2005) estudaram aspectos faciológicos e icnológicos em depósitos de plataforma que evidenciam a transição desde regiões plataformais médias até regiões de sublitoral, do Mioceno do Egito. Os depósitos de plataforma, depositados acima do nível de base de ondas de tempestade, alternam estratos com indícios de tempestade e de bom tempo, ambos com a presença de Thalassinoides. Nas localidades onde houve deposição em ambientes proximais, sob regime de alta energia e águas rasas, ocorre uma associação de Thalassinoides e de Ophiomorpha irregulaire Frey, Howard \& Prior, 1978. Nestes depósitos mais rasos também os estratos se tornam mais detríticos e abundantes em foraminíferos bentônicos, caracterizando um ambiente de sublitoral. A medida que os depósitos gradaram para batimetrias mais rasas, apenas Ophiomorpha nodosa ocorre, enquanto que Thalassinoides desaparece, caracterizando uma situação de intermaré.

Provavelmente as condições de profundidade que fizeram a icnofácies Cruziana permanecer durante a deposição da Formação Maria Farinha Inferior na região da mina Poty, se devam, novamente, a uma situação de variação lateral de fácies, como visto para o topo da Formação Gramame na Ponta do Funil.

Assim a pesquisa sugere que a Formação Maria Farinha Inferior foi depositada sob condições cada vez mais rasas ao longo do Paleoceno. Ocorreu uma gradual sucessão da icnofácies Cruziana para Skolithos, embora, seja claro que em alguns locais estas icnofácies, possivelmente se intercalaram, devido a variações topográficas e ambientais da bacia.

Icnofácies - Formação Maria Farinha Superior? Os primeiros autores a relatarem aspectos icnológicos da Formação Maria Farinha Superior? foram Muniz \& Almeida (1989), que identificaram a presença de icnitos de perfurações em conchas de moluscos e esqueletos de corais, e identificaram os icnogêneros Entobia Bron, 1837 e Caulostrepsis Clarke, 1908. Este material é procedente, principalmente da região de praias correspondente a faixa entre Jacumã e Tambaba (Figura 1).

Almeida (2000) estudou estes calcários, atribuídos aqui, informalmente, como Formação Maria Farinha Superior?. O autor registrou os icnogêneros Ophiomorpha, Lundgren, 1891, Trypanites Mägdefrau, 1932, Gastrochaenolites Leymerie, 1842, Rogerella De Saint-Seine, 1951, Caulostrepsis Clarke, 1908 e Entobia Bronn, 1838. Estes icnofósseis estão associados a perfurações em ambientes de costas rochosas, leitos de acúmulo de ossos e conchas ou substratos duros como colônias recifais (Buatois et al., 2002). Geralmente estão associados a horizontes de descontinuidade com reduzida taxa de deposição, permitindo a bioerosão do substrato duro, e a formação de hiatos estratigráficos (Pemberton \& MacEachern, 1995; Taylor \& Wilson, 2003). Almeida (2000) identificou seis icnogêneros (Ophiomorpha, Entobia, Rogerella, Caulostrepsis, Gastrochaenolites e Trypanites), o que também representa uma diversidade, em geral, maior do que a verificada nas outras litofácies carbonáticas.

O presente estudo verificou que nos estratos das praias de Jacumã e Tabatinga, Ophiomorpha ocorre em níveis associados à ação de tempestades (Figuras 10a, 10b e 10c), intercalado com níveis de parada na sedimentação, hardgrounds. Alguns afloramentos exibem intensa trama de galerias de Ophiomorpha, intercalados com níveis carbonáticos com acúmulo de moldes de 


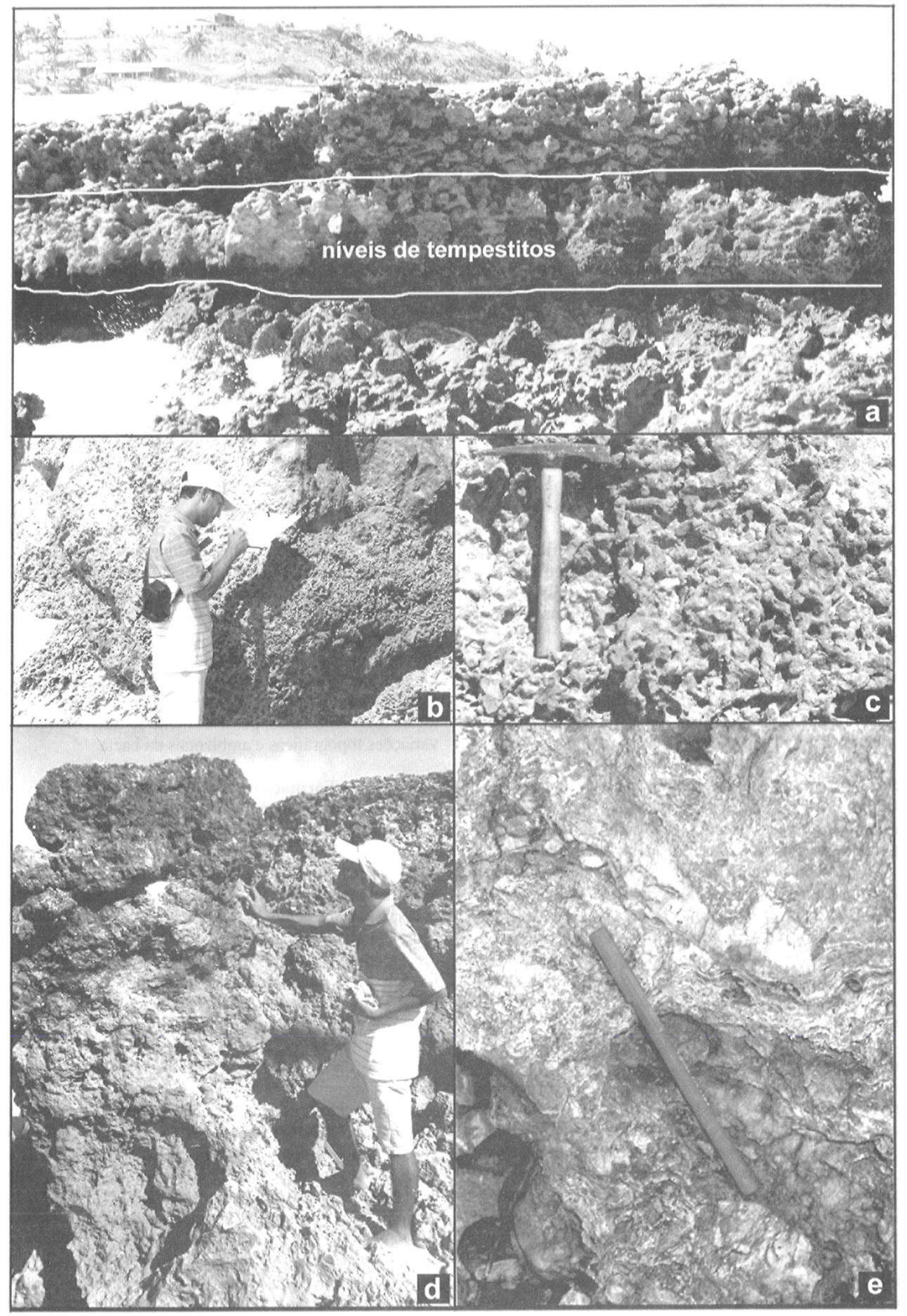

Figura 10 - Afloramentos da Formação Maria Farinha Superior? a) níveis de calcário com tempestitos e Ophiomorpha nodosa Lundgren 1891, praia de Tabatinga, Paraíba; b) afloramento mostrando espesso nível de tempestitos com tramas de Ophiomorpha, praia de Tabatinga; c) detalhe de (b) mostrando intensa trama de Ophiomorpha; d) calcários recifais, praia de Coqueirinho, Paraiba. d) detalhe exibindo niveis algálicos sobrepostos a esqueletos de corais. 
conchas, demonstrando a ocorrência de eventos de alta energia. É possível que estes níveis representassem áreas de deposição carbonática entre os bancos recifais (Figuras 10a e 10d). Na praia de Coqueirinho ocorrem afloramentos esparsos com restos destas frentes recifais e a ocorrência dos icnogêneros Trypanites e Entobia. Na Figura 10e, é possível notar o detalhe do afloramento mostrado na figura $10 \mathrm{c}$, onde foram reconhecidas esteiras algálicas, onduladas, sobre moldes de esqueletos de corais.

Malpas et al. (2005) também observaram que, com o incremento do raseamento das condições marinhas os icnogêneros Gastrochaenolites e Entobia se tornam constantes, encontrados em conchas de ostreídeos, tubos de vermes serpulíedeos, rodólitos algálicos, corais solitários, equinóides e briozoários. Segundo estes autores a associação de Gastrochaenolites e Entobia, juntamente com ostreídeos e corais sugere uma lâmina d'água de poucos metros, e são indícios da cimentação do fundo marinho durante redução da taxa de sedimentação, produzindo hardgrounds e prolongados períodos de hiato sedimentar, A partir destes caracteres, os autores atribuíram estas condições a icnofácies Trypanites. Outros trabalhos apontam conclusões semelhantes em relação à identificação da icnofácies Trypanites, considerando aspectos sedimentológicos e paleoambientais (Frey \& Pemberton, 1984; Pemberton \& MacEachern, 1995; Buatois et al., 2002; Taylor \& Wilson, 2003). Os calcários recifais, observados por esta pesquisa exibem aspectos icnológicos e sedimentológicos que apontam para as icnofácies Trypanites ou Entobia.

A icnofácies Trypanites é caracterizada por substratos duros como costões rochosos (beachrocks e bancos recifais), ou substratos duros compostos por leitos de acúmulo de conchas e esqueletos, onde predomina a bioerosão de substratos consolidados (Frey \& Pemberton, 1984; Pemberton \& MacEachern, 1995; Buatois et al., 2002; Taylor \& Wilson, 2003; Fernandes et al., 2002).

Segundo Buatois et al. (2002), a icnofácies Trypanites contém perfurações cilíndricas em forma de gota de vaso e de "U" em substrato duro, as quais correspondem a icnitos de habitação de organismos suspensívoros ou predadores passivos. Os icnogêneros característicos desta icnofácies seriam: Trypanites, Gnathichnus, Entobia, Gastrochaenolites e Rogerella (Frey \& Pemberton, 1984; Pemberton \& MacEachern, 1995; Buatois et al. 2002).

A icnofácies Entobia compreende superfícies de descontinuidade de sedimentação que ficam por muito tempo expostas onde dominam perfurações de habitação como Rogerella (Fernandes et al., 2002). Também, Buatois et al. (2002), afirmaram que, a icnofácies Entobia, caracteriza grandes períodos onde predomina a ação bioerosiva dos organismos sem a interrupção por parte de eventos de sedimentação o que resulta na destruição das perfurações superficiais devido à atividade dos perfuradores profundos. Neste caso os moluscos biválvios perfuradores e bissados, assim como as esponjas são os organismos produtores dominantes. Os icnogêneros característicos desta icnofácies são: Entobia, Caulostrepsis e Gastrochaenolites (Fernandes et al., 2002).

A partir das observações de campo e dos dados bibliográficos disponíveis, esta pesquisa sugere, que a icnofácies mais provável para a Formação Maria Farinha Superior? seja Trypanites?. Não obstante, estudos mais detalhados, podem elucidar esta questão em relação a estes depósitos recifais.

Integração dos Dados Como resultado da integração dos dados, a Tabela 1 mostra um quadro comparativo dos resultados obtidos, bem como uma interpretação das icnofácies e dos ambientes associados. Levando-se em conta o estudo das seqüências deposicionais estudadas a pesquisa sugere que durante o
Maastrichtiano predominou, na região de plataforma, onde hoje está a faixa costeira da bacia, uma condição de plataforma média, rasa, predominantemente carbonática sob um regime de mar alto (highstand system tract), relacionado à icnofácies Cruziana (Tabela 1). A partir do Maastrichtiano Superior a fase regressiva teve início, estabelecendo condições de plataforma interna a sublitoral em algumas áreas desta faixa. Esta mudança foi provocada, provavelmente, por modificações tectônicas locais, associadas a uma queda do nível eustático global (Barbosa et al., 2003; Barbosa, 2004). Durante esta fase as icnofácies Cruziana e Skolithos se intercalaram em algumas áreas (Tabela 1), enquanto esta última prevaleceu durante o final do Paleoceno.

Os depósitos recifais eocênicos estão separados da Formação Maria Farinha Inferior, provavelmente, por uma discordância, e mostram o estabelecimento de condições de plataforma interna restrita a litoral caracterizado por franjas de corais e lagunas costeiras rasas (Tabela 1). Este período, provavelmente, coincidiu com o estabelecimento de um trato de mar baixo (lowstand system tract) após um evento regressivo, com exposição e erosão da plataforma caracterizando um limite de seqüências.

A Figura 11 mostra um modelo de plataforma em rampa e seus ambientes, modificado de Burchete \& Wright (1992), onde estão indicados os prováveis ambientes onde cada unidade foi depositada bem como a icnofácies associada.

CONCLUSÕES As unidades carbonáticas da Bacia da Paraíba apresentam uma distribuição espacial complexa. A Formação Gramame ocorre em toda a faixa costeira, enquanto que a Formação Maria Farinha apresenta indícios de que sua deposição pode conter variações laterais expressivas de sua faciologia, e ocorrência de hiatos.

A Formação Gramame foi depositada sob o domínio da icnofácies Cruziana, como já havia sido sugerido por Muniz (1993). A Formação Maria Farinha Inferior, que ocorre na Sub-Bacia Olinda, apresenta uma transição da icnofácies Cruziana para a icnofácies Skolithos, e a Formação Maria Farinha Superior, que ocorre na Sub-bacia Alhandra, apresenta, provavelmente, a icnofácies Trypanites?. A pesquisa registrou, pela primeira vez, os icnogêneros: Planolites?, Palaeophycus e Gyrolithes para a Formação Gramame.

Por fim, esta pesquisa sugere a execução de trabalhos de mapeamento geológico nos calcários da Sub-bacia Alhandra que possam formaliza-los ou não como nova unidade, seja formação ou membro, já que parecem estar separados por descontinuidade temporal da Formação Maria Farinha que ocorre na Subbacia Olinda.

Agradecimentos Ao PRH-26/UFPE e ao PRH/ANP pelo apoio através da bolsa de estudos que permitiu a execução deste trabalho. Ao Dr. Mário Lima Filho, pelas discussões pertinentes e ao Dr. Ebenezer Moreno de Souza pelo apoio nas pesquisas de campo. Ao Laboratório de Geologia Sedimentar (LAGESE), do Departamento de Geologia da Universidade Federal de Pernambuco (DGEO-UFPE) pelo apoio ao desenvolvimento do projeto de reconhecimento da Bacia da Paraíba do qual esta pesquisa fez parte. Ao Dr. Vladimir de Araújo Távora, pela leitura crítica do manuscrito e importantes sugestões. 


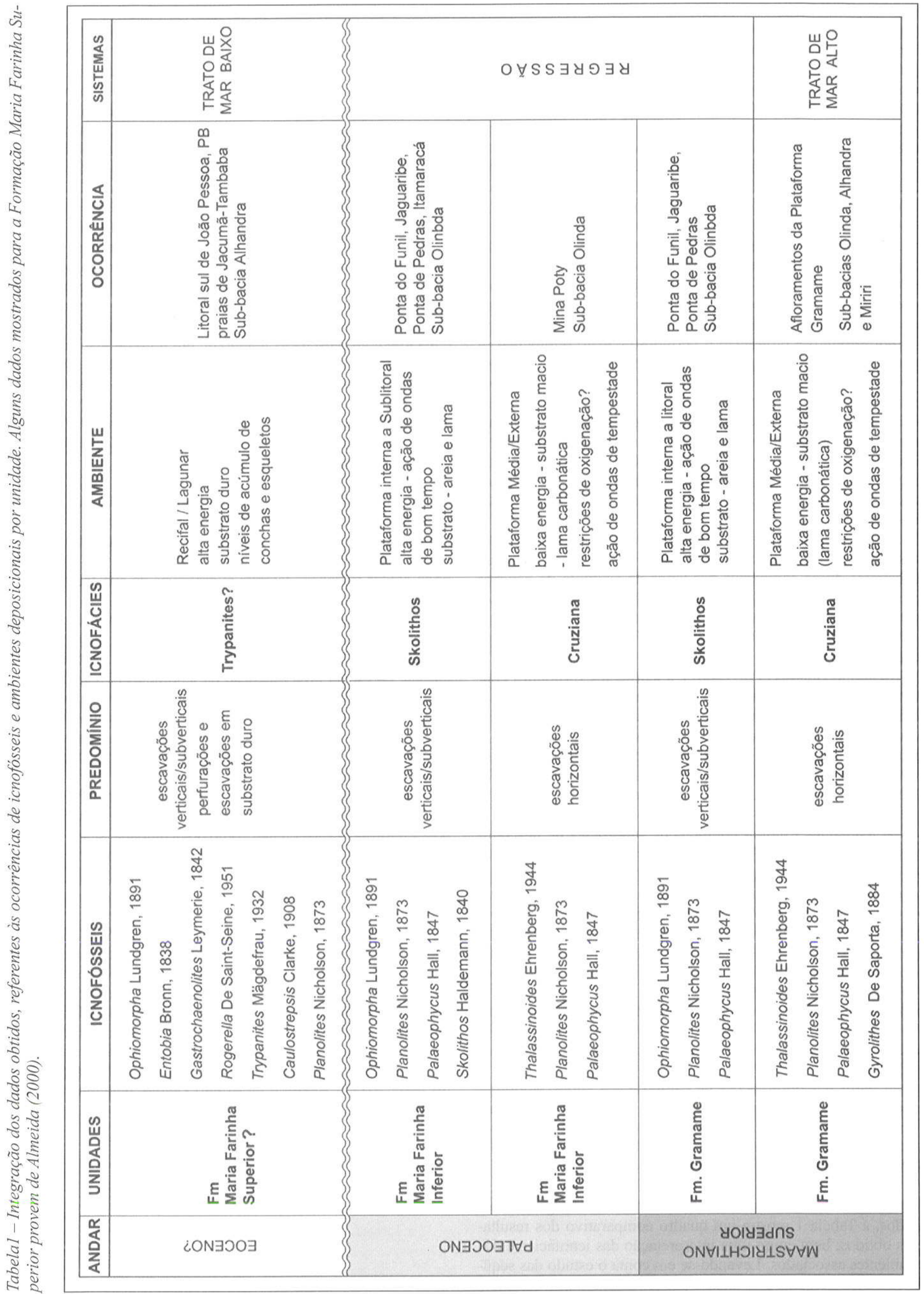




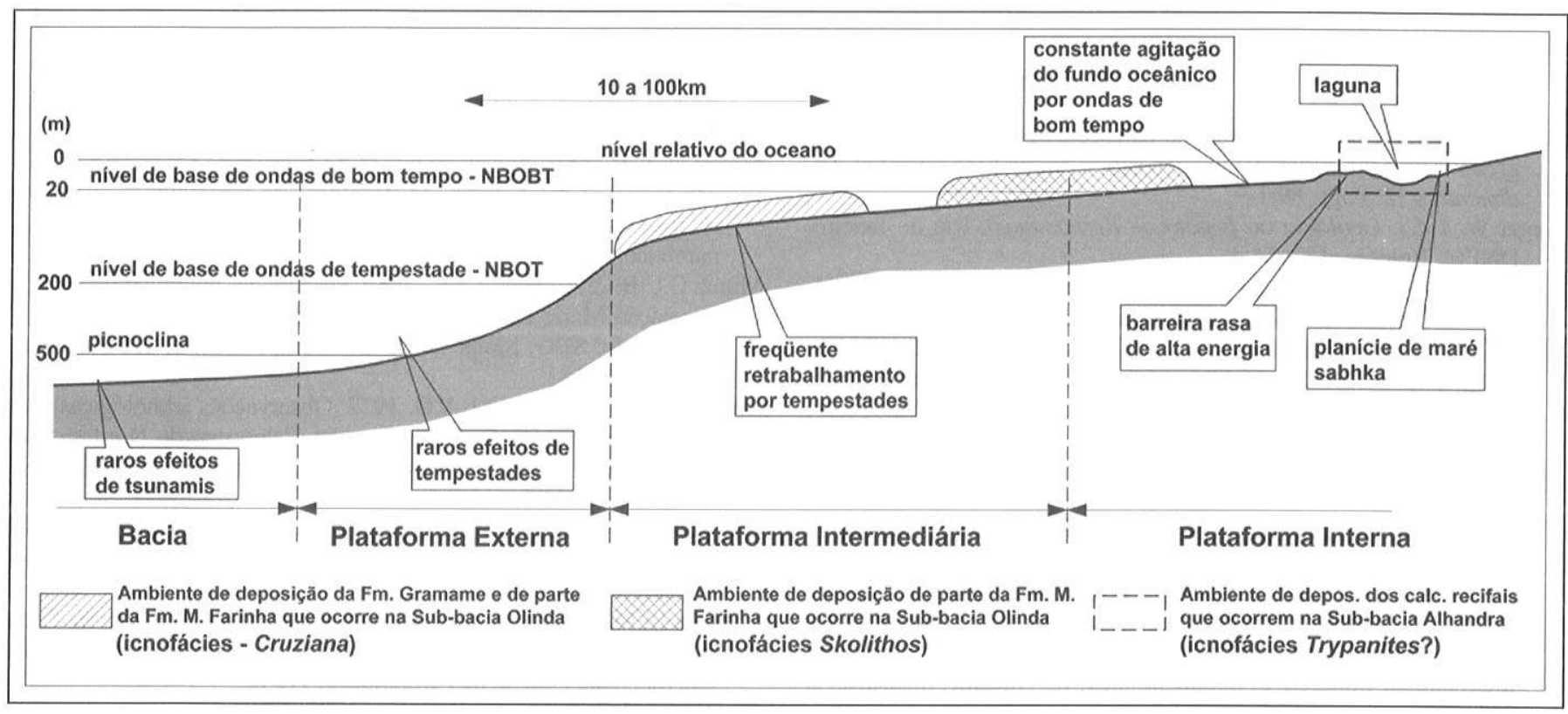

Figura 11 - Modelo deposicional das unidades carbonáticas que ocorrem na Bacia da Paraíba (modificado de Burchete \& Wright, 1992). A transição ou a sobreposição dos ambientes mostrados pode variar de acordo com a paleogeografia da bacia.

\section{Referências}

Albertão G.A. 1993. Abordagem Interdisciplinar e Epistemológica sobre as Evidências do Limite Cretáceo-Terciário, com Base em Leituras Efetuadas no Registro Sedimentar das Bacias da Costa Leste Brasileira. Dissertação de Mestrado, Departamento de Geologia da Escola de Minas da Universidade Federal de Ouro Preto, $255 \mathrm{p}$.

Almeida J.A.C. 2000. Calcários Recifais eocênicos da Formação Maria Farinha na Sub-Bacia de Alhandra, Paraiba: Aspectos Taxionômicos, Paleoecológicos, Paleoambientais e Estratigráficos. Dissertação de Mestrado, Centro de Tecnologia e Geociências, Universidade Federal de Pernambuco, $164 \mathrm{p}$.

Barbosa J.A. 2004. Evolução da Bacia Paraíba durante o Maastrichtiano- Paleoceno - Formações Gramame e Maria Farinha, NE do Brasil. Dissertação de Mestrado, Centro de Tecnologia e Geociências, Universidade Federal de Pernambuco, 230 p.

Barbosa J.A., Souza E.M., Lima Filho M.F., Neumann V.H. 2003. A estratigrafia da Bacia Paraíba: uma reconsideração. Estudos Geológi$\cos$, 13:89-108.

Beurlen K., 1967a. Estratigrafia da faixa sedimentar costeira Recife-João Pessoa. Boletins de Geologia - USP, 16(1):43-55.

Beurlen K., 1967b. Sedimentologia da faixa sedimentar costeira RecifeJoão Pessoa. Boletins de Geologia.- USP, 16(1):57-72.

Beurlen K., 1967c. Paleontologia da faixa sedimentar costeira RecifeJoão Pessoa. Boletins de Geologia - USP, 16(1):73-79.

Brett C.F., Baird G.C., Speyer S. E. 1997. Fossil Lagerstatten: stratigraphic record of paleontological and taphonomic events. In: C.F. Brett \& G.C. Baird (eds.) Paleontological events, stratigraphic,ecological and evolutionary implications. Columbia University Press, 3-40.

Brian G., Droser A., Droser M.L. 1998. Ichnofabrics and geometric configurations of Ophiomorpha within a sequence stratigraphic framework: an example from the Upper Cretaceous US western interior. Sedimentology, 45:379-396.

Botjer D.J. \& Droser M.L. 1994. The history of phanerozoic bioturbation. In: S.K. Donovan (ed.) The Palaeobilogy of trace fossils. Johns Hopkins University Press, pp.: 155176.

Bromley R.G. 1990. Trace Fossils - biology and taphonomy. London, Unwin Hyman, 280p.

Bromley R.G. 1994. The palaeoecology of bioerosion. In: S.K. Donovan (ed.) The palaeobiology of trace fossils. The Johns Hopkins University Press, Baltimore, pp.: 135-152.

Bronn H.G. 1838. Lethaea geognostica. Schweizerbart, Stuttgart. v.2, 545p. (Atlas publ. 1837).

Buatois L., Mángano G., Aceñolaza F. 2002. Trazas fósiles - señales de comportamiento en el registro estratigráfico. Chubut, Museu Egidio Feruglio, $382 \mathrm{p}$.

Burchette T.P. \& Wright W. 1992. Carbonate ramp depositional systems. Sedimentary Geology, 79:3-57.

Clarke J.M. 1908. The Beginnings of dependent life. Bull. N.Y. St. Mus. 121:146.

De Saint-Seine R. 1951. Un cirripède acrothoracique du Crétacé: Rogerella lecointrei nov.gen., nov sp. C. r. hebd. Seanc. Acad. Sci., Paris, 233:1051.

De Saporta, G. 1884. Les organismes problématiques des anciennes mers. G. Masson, Paris.

Ehrenberg K. 1944. Ergänzende bemerkungen zu den seinerzeit aus dem Miozän von Burgschleinitz beschriebenen Gangkern und Bauten dekapoder Krebse. Paläont. Z., 23:354.

El Gadi M.S.M. \& Brookfield M.E. 1999. Open carbonate ramp facies, microfacies and paleoenvironments of the Gramame Formation (Maastrichtian), Pernambuco-Paraiba Basin, Brazil. Journal of South Am. Earth Sciences, 12:411-433.

Fauth G. \& Koutsoukos E.A.M. 2002. Paleoecological inferences from marine ostracode assemblage of the Maastrichtian and Danian in the Pernambuco-Paraíba Basin. In: Simpósio sobre o Cretáceo do Brasil, 4, Boletim de Resumos, São Pedro, p. 261-265.

Feijó F.P. 1994. Bacia Pernambuco-Paraíba. Boletim de Geociências da Petrobrás, 8(1):143-148.

Fernandes A.C.S., Borghi L., Carvalho I.S., Abreu C.J. 2002. Guia dos icnofósseis de invertebrados do Brasil. Rio de Janeiro, Interciência, $260 \mathrm{p}$.

Frey R.W. \& Pemberton S.G. 1984. Trace Fossil Facies Models. In: R. G. Walker, (ed.) Facies Models. Ontário, Geosciences Canadá, 189207.

Frey R.W., Howard J.D., Pryor W.A. 1978. Ophiomorpha: its morphologic, taxonomic, and environmental significance. Palaeogeography, Palaeoclimatology, Palaeoecology, 23:199 229.

Haldemann S.S. 1840. Supplement to number one of "A monograph of the Limniades, and other fresh-water univelve shells of North America",containing descriptions of apparently new animals in different classes, and the names and characters of the subgnera in Paludina and Anculosa. Philadelphia, 3 p. 
Hall J. 1847. Descriptions of the organic remains of the lower division of the New York System. New York Natural History Survey, Paleontology of New York, v.1, 362p.

Hunt D \& Tucker M. 1992. Stranded parasequences and the forced regressive wedghe systems tract: deposition during base-level fall. Sedimentary Geology, 89:1-9.

Kegel W. 1955. Geologia do fosfato de Pernambuco. Rio de Janeiro, DNPM. Boletim, 157, 54 p.

Leymerie M.A. 1842. Suite du mémoire sur la terrain Crétacé de Départment de l'Aube, Société Géologique de France, Mémoires, 5:1-34.

Lima F.H.O. \& Koutsoukos E.A.M. 2002. Calcareous nannofossil biostratigraphy in the Maastrichtian of the Pernambuco-Paraíba Basin, NE Brazil. In: Simpósio sobre o Cretáceo do Brasil, 6, São Pedro, Boletim de Resumos, 279-284.

Lima F.H.O. \& Koutsoukos E.A.M. 2004. Petrografia e microfácies das rochas carbonáticas da Formação Gramame (Maastrichtiano), Bacia de Pernambuco-Paraíba, NE-Brasil. In: SBG,Congresso Brasileiro de Geologia do Brasil, 42, Araxá, Boletim de resumos, CD-Rom.

Lima Filho M.F., Monteiro A.B., Souza E.M. 1998. Carbonate sections of the Paraiba and Pernambuco Basins, Northeastern Brazil: Implications for the late stages of opening of Southern Atlantic Ocean. In: International Congress of Sedimentology, 15, Alicante, Abstracts, p. 504-505.

Lima Filho M.F., Barbosa J.A., Neumann V.H., Souza E.M. 2005. Evolução estrutural comparativa da Bacia de Pernambuco e da Bacia da Paraíba. In: Simpósio Nacional de Estudos Tectônicos, 5, Curitiba. Boletim de Resumos, 45-47.

Lundgren S.A.B. 1891. Studier öfver fossilförande lösa block. Geologiska Föreningens i Stockholm Föhandlingar, 13:21-111.

Mabesoone J.M. \& Alheiros M.M. 1988. Origem da bacia sedimentar costeira Pernambuco-Paraíba. Revista Brasileira de Geociências, 18(4):476-482.

Mabesoone J.M. \& Alheiros M.M. 1991. Base Estrutural In: J.M. Mabesoone (coord) Faixa sedimentar costeira de Pernambuco, Paraiba e parte do Rio Grande do Norte. Estudos Geológicos. 10, Série B, 33-43.

Mabesoone J.M. \& Alheiros M.M. 1993. Evolution of the PernambucoParaíba-Rio Grande do Norte Basin and the problem of the South Atlantic conection. Geologie en Mijnbouw, 71:351-362.

Mägdefrau K. 1932. Über einige Bohrgänge aus dem Unteren Muschelkalk von Jena. Paläont. Z. 14:150.

Malpas J.A., Gawthorpe R.L., Pollard J.E., Sharp I.R. 2005. Ichnofabric analysis of the shallowstand marine Nukhul Formation, Miocene, Suez Rift, Egypt: implications for depositional processes and sequence stratigraphic evolution. Palaeogeography, Palaeoclimatology, Palaeoecology. 215:239-264.

Maury C.J. 1930. O Cretáceo da Parahyba do Norte. Monografia do Serviço Geológico e Mineralógico do Brasil. Rio de Janeiro, v. 8, p. 1-305.

Menor E.A. \& Amaral A.J.R. 1979. O comportamento mineralógico da sedimentação fosfática na Bacia Sedimentar Costeira PernambucoParaíba. In: Simpósio de Geologia do Nordeste, 9, Natal, Boletim de Resumos, 271-282.

Menor E.A. \& Boujo A. 2000. Geochemical features of the Maria Farinha Formation, Pernambuco-Paraíba Basin, Northeastern Brazil. In: Simpósio de Geologia do Nordeste, 18, Recife, Boletim de Resumos, p. 72.

Menor E.A., Dantas J.R.A., Sobrinho, A.C.P. 1977. A sedimentação fosfática em Pernambuco e Paraíba: revisão de novos estudos. In: Simpósio de Geologia do Nordeste, 8, Campina Grande, Boletim de Resumos, 1-27.

Morais D.M.F., Barbosa J.A., Vila Nova F., Neumann V.H., Lima Filho M.F. 2005 Evidências de neotectonismo na Bacia da Paraíba (Subbacia Olinda), NE do Brasil In: Simpósio Nacional de Estudos Tectônicos, 10, Curitiba, Boletim de Resumos, 51-53.

Morais D.M.F., Menor E., Vila Nova F., Pereira E., Barbosa J.A., Lima
Filho M., Neumann V.H. 2004. Evidências de Neotectonismo na Bacia Paraíba (Sub-bacia Olinda), NE do Brasil. In: Simpósio da Região Nordeste Sobre Pesquisa e Desenvolvimento para o Setor de Petróleo e Gás Natural, 1, Recife, Boletim de Resumos, 29-30.

Muniz G. C.B. 1993. Novos moluscos da Formação Gramame, Cretáceo Superior dos Estados da Paraíba e de Pernambuco, Nordeste do Brasil. Departamento de Geologia, Universidade Federal de Pernambuco, Publicação Especial v.1, 202 p.

Muniz G.C.B. \& Almeida J.A.C. 1989. Perfurações em invertebrados da Formação Maria Farinha, Terciário Inferior da Bacia PernambucoParaíba. In: SBG, Simpósio de Geologia, Nordeste, 13, Fortaleza, Atas, p. 184-187.

Muniz G.C.B. \& Ramirez L.V.O. 1977. Observações ichnológicas preliminares na Formação Maria Farinha, Paleoceno do Nordeste. In: Simpósio de Geologia do Nordeste, 8, Campina Grande, Boletim de Resumos, 111-119.

Nicholson H.A. 1873. Contributions to the study of the errante annelides of the older Paleozoic rocks, Proceeedings of the Royal Society of London, 21:90-288.

Oliveira M.M.F. 1978. Estudo Faciológico da Formação Maria Farinha. Dissertação de Mestrado, Centro de Tecnologia e Geociências, Universidade Federal de Pernambuco, 113 p.

Pemberton S.G. \& MacEachern J.A. 1995. The sequence stratigraphic significance of trace fossils: examples from the Cretaceous Foreland Basin of Alberta, Canada. In: J.C. Van Wagoner \& G.T. Bertram (Eds.) Sequence stratigraphy of foreland basins. American Association of Petroleum Geologists Memoir, v. 64, p. 429-475.

Pemberton S.G. \& MacEachern J.A. 1997. The ichnological signatures of storm deposits: the use of trace fossils in event stratigraphy. In: C.E. Brett \& G.C. Baird (eds) Paleontological events. Columbia University Press, 73-109.

Scasso R.A., Olivero E.B., Buatois L.A. 1991. Lithofacies, biofacies, and ichnoassemblage evolution of a shallowstand submarine volcaniclastic fan-shelf depositional system (Upper Cretaceous, James Ross Island, Antarctica). Journal of South American Earth Sciences, 4(3):239-260

Schlicht P., Bengtson P., Hambach U., Krumsiek K., Koutsoukos E.A.M. 1999. Ciclos de calcário e marga do Maastrichtiano da Bacia Pernambuco-Paraíba (NE Brasil) - Evidências de imposição orbital? In: Simpósio Sobre o Cretáceo do Brasil, 5, Serra Negra, Boletim de resumos, v. 1, p. 121-124.

Silva V.G., Figueiredo F.J., Carvalho L.B., Azevedo S.A.K. 2001. Vertebrate assemblage from the Maria Farinha Formation after K-T Boundary. N. Jb. Geol. Paläont. Abh. 219(3):261-284.

Souza E. M. 1998. Levantamento radiométrico das unidades estratigráficas da Bacia Paraiba. Dissertação de Mestrado, Universidade Federal de Pernambuco, $152 \mathrm{p}$.

Souza E.M. 2006. Estratigrafia da seqüência clástica inferior (andares Coniaciano-Maastrichtiano Inferior) da Bacia da Paraiba, e suas implicações paleogeográficas. Tese de Doutoramento, Centro de Tecnologia e Geociências, Universidade Federal de Pernambuco, $350 \mathrm{p}$.

Taylor P.D. \& Wilson M.A. 2003. Palaeoecology and evolution of marine hard substrate communities. Earth-Science Reviews, 62:1-103.

Távora V.A \& Miranda M.C.C. 2004. Sistemática e tafonomia de uma fáunula de crustáceos decápodes da Formação Maria Farinha (Paleoceno), Estado de Pernambuco, Brasil. Revista Brasileira de Paleontologia, 7(1):45-52.

Tinoco I.M. 1971. Foraminiferos e a passagem entre o Cretáceo e o Terciário em Pernambuco. Tese de Doutoramento, Instituto de Geociências e Astronomia, Universidade de São Paulo, 147 p.

Manuscrito A1629

Aprovado em 25 de outubro de 2006 